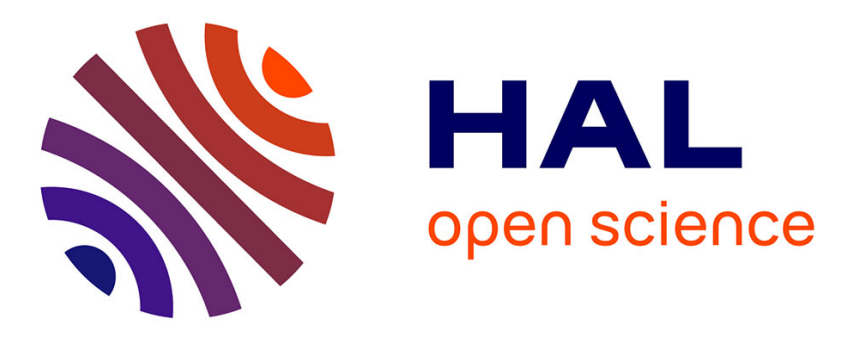

\title{
Two-phase reservoir: development of a transient thermo-hydraulic model based on bond graph approach with experimental validation
}

Mohamed Kebdani, Geneviève Dauphin-Tanguy, Antoine Dazin, Roni Albach, Patrick Dupont

\section{To cite this version:}

Mohamed Kebdani, Geneviève Dauphin-Tanguy, Antoine Dazin, Roni Albach, Patrick Dupont. Twophase reservoir: development of a transient thermo-hydraulic model based on bond graph approach with experimental validation. Mathematical and Computer Modelling of Dynamical Systems, 2016, 10.1080/13873954.2016.1259635 . hal-01445833

\section{HAL Id: hal-01445833 \\ https://hal.science/hal-01445833}

Submitted on 25 Jan 2017

HAL is a multi-disciplinary open access archive for the deposit and dissemination of scientific research documents, whether they are published or not. The documents may come from teaching and research institutions in France or abroad, or from public or private research centers.
L'archive ouverte pluridisciplinaire HAL, est destinée au dépôt et à la diffusion de documents scientifiques de niveau recherche, publiés ou non, émanant des établissements d'enseignement et de recherche français ou étrangers, des laboratoires publics ou privés. 
Two-phase reservoir: Development of a transient thermo-hydraulic model based on Bond Graph approach with experimental validation.

M. Kebdani ${ }^{\mathrm{a}}$, G.Dauphin-Tanguy ${ }^{\mathrm{a}}$, A. Dazin ${ }^{\mathrm{b}}, \mathrm{R}$.Albach ${ }^{\mathrm{c}}$, P. Dupont ${ }^{\mathrm{d}}$

${ }^{a}$ Ecole Centrale de Lille/ CRIStAL UMR CNRS 9189, CS 20048, 59651 Villeneuve d'Ascq. France. ${ }^{b}$ Arts et Métiers Paris Tech/ LML UMR CNRS 8107, Boulevard Louis XIV, 59000 Lille. France. ${ }^{c}$ Atmostat R.Albach, 31 Rue René Hamon, 94815 Villejuif. France. ${ }^{d}$ Ecole Centrale de Lille/LML UMR CNRS 8107,CS 20048, 59651 Villeneuve d'Ascq. France. 


\begin{abstract}
The main purpose of the project FUI THERMOFLUID is to study the feasibility of a new electronic cooling system embedded on flying objects (missile, satellite, and airplane). The technology chosen consists of a pumped two-phase flow cooling loop (PTPFL). It is an innovative technology with a transport capacity of the thermal power up to $10 \mathrm{MW} . \mathrm{m}$, exceeding in this way the performance of all other technologies. A PTPFL is a cooling loop based on the exploitation of the latent heat properties of the fluid trapped inside the loop, and moved by a pump. The components constituting a PTPFL are: a two-phase reservoir (TP-R), a mini- channels evaporator, a brazed plate condenser, a pump and pipes. The global research work is devoted to propose a dynamic model and experimental validation of the PTPFL. The present article is exclusively dedicated to the TP-R two-phase reservoir (TP-R). Indeed this element plays a key role in the functioning of PTPFL. Historically, the TP-R did not equip the first cooling loop. However, due to its advantages its introduction was essential. The developed dynamic model will be used in another work to predict the thermal hydraulic efficiency of the PTPFL from its mechanical and fluidic parameters, to conduct the study of transitional regimes and instability problems, and provides an original tool dedicated to design the TP-R in function of the thermal power levels to be evacuated and the selected refrigerant. The bond graph methodology is adopted for modeling works because of its energetic approach and multi physics character of the studied system.
\end{abstract}

The new model proposed in this article has many originalities: First, it is based on bond graph approach. Nowadays, the open literature shows that no bond graph model has been developed for such thermo-fluid system. Second, the dynamic model of TP-R pays great attention to phenomena that have never been taken into account in works cited in the present article, such as evaporation and condensation. Third, different conducto-convective heat exchanges are modeled without any experimental recalibration of the thermal exchange coefficients, unlike models proposed in the literature. In fact, all coefficients are systematically calculated using adequate correlations.

Keywords: Bond Graph; two-phase flow; dynamic; transient; heat transfer coefficient; convection; conduction; cooling loop; modeling, Presurizer. 


\section{INTRODUCTION AND STATE OF THE ART}

An electronic device generates heat flows that require thermal management. For example the limit junction temperature of a silicon chip is about $125^{\circ} \mathrm{C}$; if it is exceeded an important risk of malfunction and degradation is considered. Furthermore, the volume density of the power dissipated by Joule effect in a converter is quadrupled every four years, providing values that could reach $100 \mathrm{w} / \mathrm{cm}^{2}$ for the arrival of 2020 [Ser07]. The cooling of electronic devices based only on exchanges by natural convection is dedicated to low power. Indeed, the heat transfer coefficient remains low: $15 \mathrm{~W} / \mathrm{cm}^{2}$ [Rio16]. Furthermore, the finned radiators have exchange coefficients up to: $35 \mathrm{~W} / \mathrm{cm}^{2}$ [Rio16]. For higher power, cooling loops are more adapted. The pumped two-phase flow cooling loop (PTPFL) is an effective technology in terms of heat flow transport capacity: $10 \mathrm{MW} . \mathrm{m}$ [LAU06], with high level adaptability and an exchange coefficient up to: $600 \mathrm{~W} / \mathrm{cm}^{2}$.

A (PTPFL) is a cooling system composed of five components as shown in Figure 1. A succinct description of the role accomplished by each element is given in a previous work [KEB14]. The current article deals especially with the two-phase reservoir noted TP-R in Figure 1.

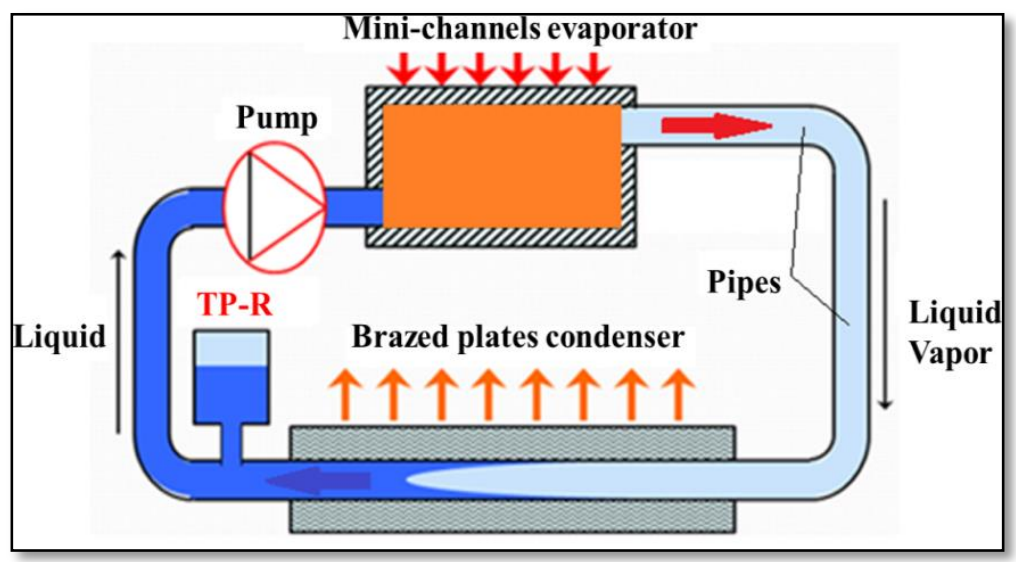

Figure 1 : Overall architecture of a PTPFL

The first part of the current research work presents the different functions insured by a TP-R. Moreover, a modeling state-of-the-art is conducted in order to highlight better our contributions. A second part is devoted to describe the new dynamical model based on bond graph methodology. This model takes into consideration the physics of evaporation and condensation phenomena. Convection and conduction flows are modeled without any need of experimental recalibration of thermal exchange coefficients. The thermo-hydraulic behavior of the water and the steam filling the TP-R is validated thanks to experimental tests presented and detailed in the third part.

\subsection{Main functions of a: TP-R}

The TP-R is component of the PTPFL. It fulfills simultaneously three roles during the functioning of the system.

\section{a) Thermodynamic control of the PTPFL}

The lower part of the TP-R is filled with liquid. The vapor occupies the upper part as shown in Figure 2. Thus, it is possible to control the liquid pressure by acting on its temperature, using a suitable heating device. Then, taking into account some pressure losses it is possible 
to command the pressure within the evaporator and the condenser as well. Consequently, the saturation temperature is controlled inside the evaporator. Thanks to this temperature, the saturated nucleate boiling is launched allowing an efficient cooling based on the latent heat.

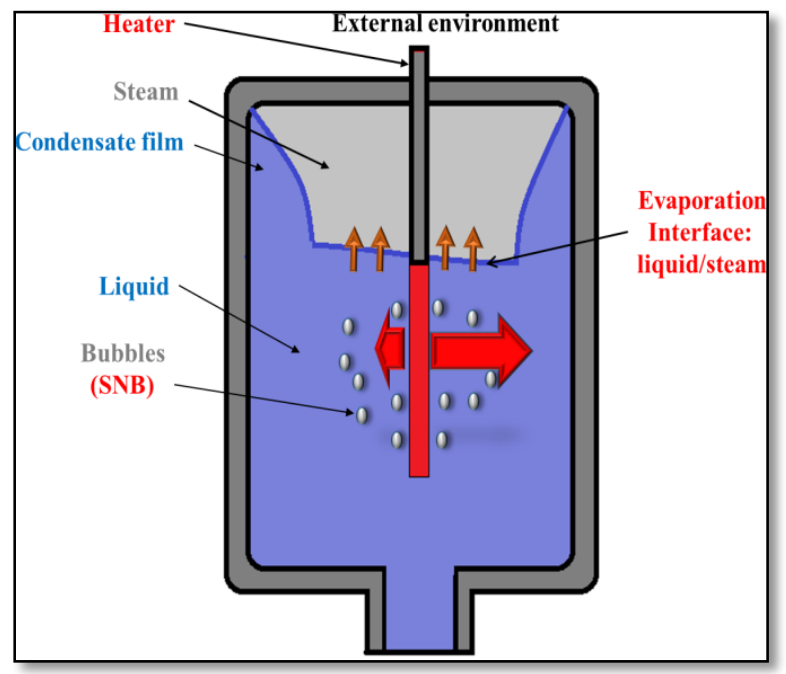

Figure 2 : representation of evaporation and condensation phenomena.

\section{b) The TP-R, a volume of control}

It is used to compensate for the expansion phenomenon of fluid. In fact, during PTPFL functioning, the fluid trapped in the loop passes through several transitional phases, during which its volume increases under the effect of heat received by the device to be cooled. This volume variation induces a pressure rise, jeopardizing in this way the whole structure of the loop. With the TP-R this risk does not exist, since the liquid volume in excess is directly injected into the TP-R.

\section{c) TP-R is a pump protector}

The TP-R permits to the pump to function without cavitation. Actually, it is necessary to heat first the liquid contained in the TP-R. The rise of liquid temperature induces an increase in pressure throughout the loop. Thus, the fluid filling the loop sees its pressure increasing while its initial temperature is maintained constant. These thermodynamic conditions force the vapor to condensate in the loop, and so provide a secure pump starting without cavitation.

\subsection{State-of-the-art of TP-R modeling}

Up to now, unlike Capillary Pumped Loops (CPL), the published literature lists absolutely no research work dedicated to PTPFL modeling. Nowadays, our research work [KEB14] is the only detailed work dedicated to PTPFL technology and published in the open scientific literature. However, TP-R remains a common component between the two cooling technologies (CPL) and (PTPFL). Then, it is important to carry on a state-of-the-art on how this component is modeled in the CPL to better position our work and highlight its originality compared to the previous works.

\section{a) Classification of models}

Considering the large number of CPL modeling [WMN08] and [FHP11] made since their first introduction in 1978, an overall classification of existing models is proposed and structured as shown in Table 1. 


\begin{tabular}{|c|c|c|c|c|}
\hline \multirow{2}{*}{ Author } & \multicolumn{2}{|c|}{ steady model } & \multicolumn{2}{c|}{ Unsteady model } \\
\hline & $\begin{array}{c}\text { analytical } \\
\text { solution }\end{array}$ & $\begin{array}{c}\text { Numerical } \\
\text { solution }\end{array}$ & $\begin{array}{c}\text { analytical } \\
\text { solution }\end{array}$ & $\begin{array}{c}\text { Numerical } \\
\text { solution }\end{array}$ \\
\hline Furukawa [FUR06] & $\checkmark$ & & & \\
\hline Dolgirev [DGMK78] & $\checkmark$ & & & \\
\hline Ku [KKM87] & & & & \\
\hline $\begin{array}{c}\text { Kaya et Hoang } \\
\text { [KH99] }\end{array}$ & $\checkmark$ & & & $\checkmark$ \\
\hline Kaya [KPGT07] & & & & \\
\hline Chuang [Chu03] & $\checkmark$ & & & $\checkmark$ \\
\hline Hamdan [HGH03] & $\checkmark$ & & & $\checkmark$ \\
\hline Pouzet [PJP04] & & & & \\
\hline Launay[LPDJ07] & & & & \\
\hline
\end{tabular}

Table 1: classification of TP-R modeling works.

\section{b) Results of the state-of-the-art}

First, it turns out that steady models are predominant with analytical solutions. The state-ofthe-art reveals that few numerical models are developed for simulation in steady state. In fact, numerical tools remain reserved for unsteady studies (transient phenomena, instability, thermal cycling ...) where important thermo hydraulic coupling must be taken into account. Also, the late appearance of numerical models is mainly due to significant advances in the field of the computing science.

The new model proposed in this article is dynamical with numerical solutions; it differs from existing models by the large number of phenomena modeled as well as the minimum number of simplifying hypotheses. The following phenomena are treated in the proposed model but not in other models:

Evaporation at the liquid / vapor interface.

$>$ Condensation on walls (Nusselt theory).

$>$ Multiple heat exchange.

$>$ Various configurations of flow (cartridge / liquid).

$>$ Longitudinal conduction.

$>$ Exchanges with the outside.

\section{MODEL DESCRIPTION OF TP-R}

\subsection{Physical description of modeled phenomena}

$\rightarrow$ The liquid receives power density $q\left(w / m^{2}\right)$ from the cartridge, which makes its temperature increasing. If this one reaches the saturation temperature $T_{s a t}$ corresponding to the pressure $P_{l i q}$ in the liquid volume, nucleate boiling is therefore initiated. So, vapor bubbles arise in the liquid. Then, bubbles ascend in the form of convection cells, to the interface where they are vaporized as represented in Figure 2.

The steam temperature is the result of a complex process of evaporation happening at the liquid-vapor interface coupled with a process of condensation at the inner surface of the TP$\mathrm{R}$ as shown in Figure 2. Actually, the steam in contact with the inner wall of the TP-R is likely to condense when its temperature is greater than the one of the wall $T_{\text {wall }}$ int $_{\text {sp }}$. This phenomenon, called film condensation, which could coexist with the evaporation phenomenon, leads to the formation of a continuous liquid film of width $\delta_{\text {film }}$ located between the steam and the wall as shown in Figure 2. The width of the film $\delta_{\text {film }}$, the Mass 
flow of evaporation $\dot{m}_{\text {evap }}$ and condensation $\dot{m}_{\text {cond }}$, the enthalpy flow rate generated by the condensation $\dot{H}_{\text {cond/liq }}$ and evaporation $\dot{H}_{\text {liq/vap }}$ are modeled. The thermal flow rate exchanged between the vapor and the wall $\dot{H}_{\text {vap/wall_int }}$ sup $_{\text {in }}$ is also modeled, as can be seen in Figure 3.

$\rightarrow$ A heat flow $\dot{H}_{c a r t / l i q}$ exists between the heating element and the liquid mass. A part of this heat flow $\dot{H}_{\text {liq/wall_int }}$ if is transferred, by natural convection to the wall. A certain quantity $\dot{Q}_{\text {long }}$ is propagated by conduction along the material constituting the TP-R. This heat flow $\dot{Q}_{\text {long }}$ increases the temperature of the upper wall $T_{\text {wall } \_ \text {int }}$ sup $_{\text {p }}$ which is in contact with the vapor, and consequently intervenes in the condensation phenomena taking place in this part of the TP-R. Finally, other portions of heat flow noted: $\dot{H}_{\text {air/wall_ext }}$ and $\dot{H}_{\text {air } / \text { wall_ext }}$ are transferred by natural convection from the wall (lower and upper parts) to the outside of the TP-R. The Figure 3 summarizes the distribution of the flows, above mentioned.

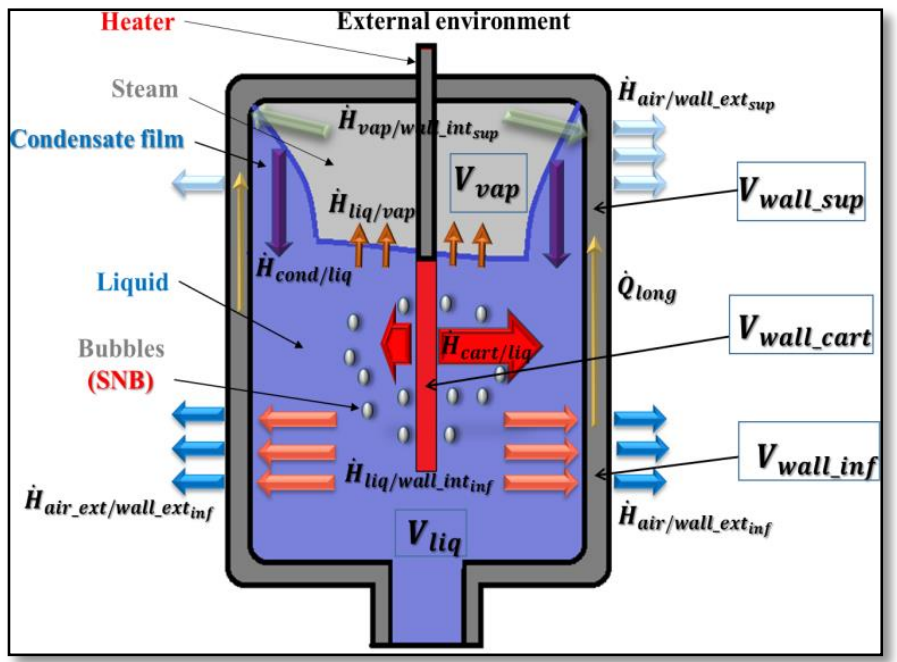

Figure 3 : Distribution of the various heat flows within the TP-R.

Finally, it is particularly important to remind the reader that no identification of the thermal exchange coefficients was made, contrary to modeling works found in the literature (Pouzet stall [PJP04], Chuang [CHU03], Kaya et al. [KPGT07] Adoni et al. [AAJK07]) where an experimental identification was needed to find thermal conductance.

\subsection{Bond graph model of the TP-R}

\section{About the theory of bond graphs}

Industrial thermal fluids systems are multi-disciplinary. Their functioning involves systematically several domains of the physic (mechanic, hydraulic, thermal, chemical and electrical fields. This phenomenological complexity makes it difficult to develop a standard model based on partial differential equations.

The bond graph methodology is based on the principle of energy conservation. It allows to represent graphically the power transfer between components of a complex system. A bond graph model is a unified graphical representation for all areas of engineering science. It is based on the principle of analogy between different fields of physics. Also, a bond graph model is structural which allows simulation and analysis of the model properties (Dauphin - 
Tanguy et al, 1999) and behavioural. The bond graph allows modeling adapted to the evolutionary technological needs. In fact the model can be easily modified by adding or removing elements, permitting in this manner a modeling approach called "bottom-up" or "top down".

\section{Bond graphs or standard approaches?}

During recent decades, a significant number of tools and thermal modeling methodologies were developed for industry and research domains. These models are generally grouped into three categories: "black box models", "white box models" and " gray box models". The "black box models" simply allow a numerical solution of the problem without providing any physical interpretation of the studied system. However the "white box models" are based on the physics and explicitly describe the system. Therefore, they are more complex to generate, since they contain very few approximations, thus so many parameters. Indeed, they require a long calculation time and a large computing capacity. So the scientists used the "gray box models". These models combine the physical sense and spirit of simple models. The Bond graphs are part of this class of models. The advantage of this approach, compared to other simulation tools such as TRNSYS, is that they require writing new computer codes to model components that are not available in their libraries, while bond graphs, due to their graphic approach and with a minimum of input parameters, it is easier to model complex phenomena. Also they are very suitable for modeling the basic problems of heat transfer through a wall while TRNSYS, for example, is not dedicated to this type of problems. If the Bond graph language gives the physical structure of the system, it also gives the causal structure, in other words, the calculation structure. It provides systematically variables and equations of state.

\section{Assumptions}

- Steam is saturated.

- TP-R is composed of two volumes. See Figure 3.

$\Rightarrow$ The lower volume is exclusively liquid.

$\Rightarrow$ The upper volume is exclusively steam.

- The interface thickness separating the two volumes is neglected.

$\Rightarrow$ In the proposed model the interface separating liquid and gas is not considered at all. In reality, this phase is composed of a mixture of liquid and gas and should be taken into account in the modelling process, but studies and experimentations conducted by (Carey 1992) and (Guo 2000) for water shows that the thickness of this interface is of some nanometers. This result leads us to neglect the presence of such interface.

\section{Note:}

The interaction between liquid and vapor volumes is considered by modelling the heat exchange taking place in both directions: liquid/vapor (evaporation phenomenon) and vapor/liquid (condensation phenomenon). Also, the mass flow of evaporation and condensation reflects how both volume are linked. All these phenomena are modeled by the multiport bond graph element $\mathrm{R}$.

- No presence of non-condensable gas in the TP-R.

- Temperature and pressure are considered uniform.

- The material constituting the TP-R is assumed to be homogeneous, isotropic, of constant thermal conductivity $\lambda$.

- The refrigerant used for the simulation is water; its thermo physical features are extracted from NIST [site 1]. Specific polynomial and Gaussian correlations were developed and are listed in Annex A. 


\section{Choice of thermodynamic variables}

The product of effort and flux in a true bon graph is a power. However, to make profit of some simplifications related to the mathematical formalism, it is decided to develop a pseudo bond graph in which the product effort by flux is not a real power, but all the properties of a true bond graph remain the same.

The variables in the pseudo bond graph model are:

- Pressure and Mass flow for the hydraulic domain.

- Temperature and enthalpy flow rate (for convection) or heat flow rate (in case of conduction) for the thermal domain.

\section{Discretization of the TP-R structure}

The reservoir structure is discretized into five volumes as shown in Figure 3:

1. Liquid Volume: $V_{\text {liq }}$.

2. Steam Volume: $V_{\text {vap }}$.

3. Volume of the wall in contact with the liquid : $V_{\text {wall }}$ inf .

4. Volume of the wall in contact with the steam : $V_{\text {wall_sup }}$.

5. Volume of the heating cartridge wall: $V_{\text {wall_cart }}$.

All of these volumes are modeled by a capacitive C-element, which characterize the storage of mass and heat inside the TP-R. The mass and energy conservation equations are represented in bond graph theory by junctions: $0_{h}$ for hydraulic part, and $0_{t}$ for the thermal. Also, these two junctions reflect the assumption of pressure and temperature uniformity.

Given the mathematical form of heat exchange laws (Fourier law), thermal transfer phenomena (convection and conduction) are modeled by dissipative R-elements shown in Figure 4.

The Figure 4 is a global representation of the pseudo bond graph model, developed for the two-phase reservoir.

After the qualitative description of modeled phenomena, the conservation equations governing the dynamic behaviour of the TP-R are now presented.

The unknowns are:

- the pressure of the liquid : $P_{\text {liq }}(t)$,

- the mass of the liquid : $m_{l i q_{-} a c c}$ and the vapor mass : $m_{\text {vap_acc }}$,

- the temperature of the liquid : $T_{\text {liq }}(t)$,

- the temperature of the lower TP-R wall : $T_{\text {wall }}(t)$,

- the temperature of the upper TP-R wall : $T_{\text {wall }}(t)$,

- the temperature of the cartridge : $T_{\text {cart }}(t)$,

- the pressure of the vapor : $P_{\text {vap }}(t)$,

- the temperature of the vapor: $T_{v a p}(t)$, 
The mentioned unknowns are calculated inside $\mathrm{C}$ elements, the resolution of integral equations is performed by Runge-Kutta solver integrated in 20-sim [Site 2], a step of 0.01 has been chosen. (20-sim is a modeling and simulation program for mechatronic systems). The bond graph methodology leads us to represent the calculation formalism as follows:

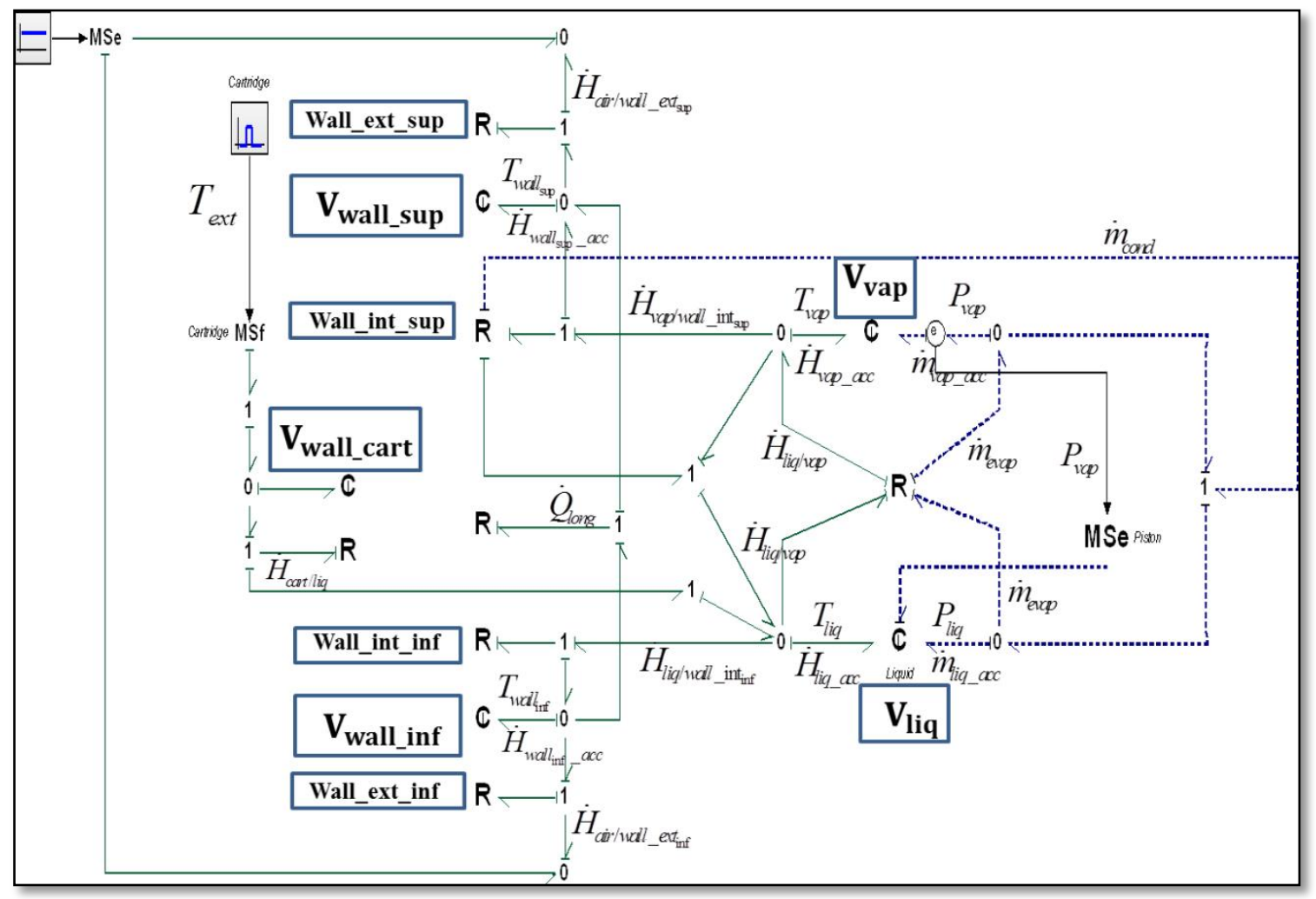

Figure 4 : Dynamic pseudo-bond graph model of TP-R.

After the qualitative description of modeled phenomena, the conservation equations governing the dynamic behaviour of the TP-R are now presented.

The unknowns are:

- the pressure of the liquid : $P_{l i q}(t)$,

- the mass of the liquid : $m_{\text {liq_acc }}$ and the vapor mass : $m_{v a p_{-} a c c}$,

- the temperature of the liquid : $T_{\text {liq }}(t)$,

- the temperature of the lower TP-R wall : $T_{\text {wall }}(t)$,

- the temperature of the upper TP-R wall : $T_{\text {wall }}(t)$,

- the temperature of the cartridge : $T_{\text {cart }}(t)$,

- the pressure of the vapor : $P_{v a p}(t)$,

- the temperature of the vapor: $T_{\text {vap }}(t)$,

The mentioned unknowns are calculated inside $\mathrm{C}$ elements, the resolution of integral equations is performed by Runge-Kutta solver integrated in 20-sim [Site 2], a step of 0.01 has been chosen. (20-sim is a modeling and simulation program for mechatronic systems). The bond graph methodology leads us to represent the calculation formalism as follows: 


\subsection{Mathematical equations governing the C-elements}

a) Volume $V_{\text {liq }}$

The pressure of the liquid $P_{l i q}(t)$ :

The liquid pressure is given by the hydrostatic law representing one of constitutive laws of the element $C_{\text {liquid }}$ :

$$
P_{\text {liq }}(t)=P_{\text {vap }}(t)+\left(\rho_{\text {liq }} \cdot g \cdot x_{\text {liq }}(t)\right)
$$

where:

$$
x_{l i q}(t)=H_{T P-R}-x_{v a p}(t)
$$

Vapor pressure $P_{\text {vap }}(t)$ is calculated by equation (18). $x_{\text {vap }}(t)$ is the height of steam in the TP$\mathrm{R}$, its expression is obtained by equation (56).

\section{The liquid mass $m_{l i q \_a c c}$}

\section{Equation of mass conservation}

The mass storage in the liquid volume $V_{l i q}$ is modeled by the 2 ports element $C_{l i q}$, as shown in Figure 5.

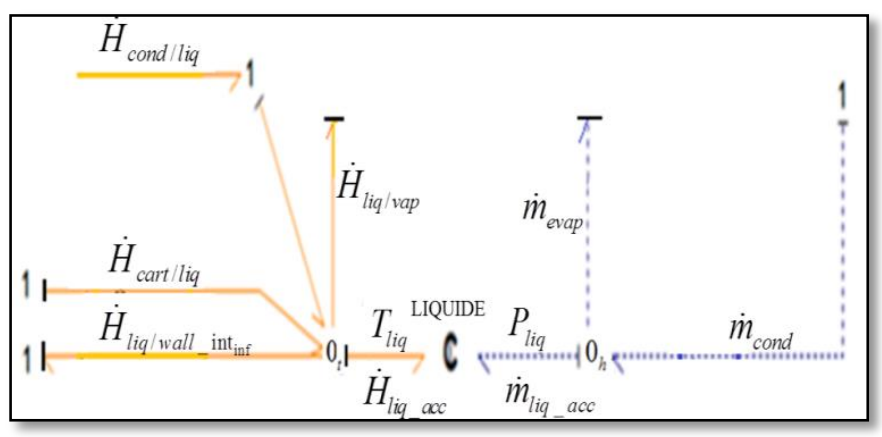

Figure 5 : Bond graph model of the liquid volume.

The hydraulic junction $0_{h}$ allows to write the hydraulic flow balance:

$$
\dot{m}_{\text {liq_acc }}=\dot{m}_{\text {cond }}-\dot{m}_{\text {evap }}
$$

Mass flow of condensation and evaporation are respectively given by equations (52) and (58). Then, we have:

$$
m_{l i q_{-} a c c}(t)=\int_{t} \dot{m}_{l i q_{-} a c c} \cdot d t+m_{l i q, 0}
$$

$m_{l i q, 0}:$ the initial mass of the fluid contained in the TP-R

\section{Remark}

$$
m_{l i q, 0}=\rho_{l i q, 0}\left(T_{0}\right) \cdot V_{l i q, 0}
$$

Initially, the liquid and vapor are in thermodynamic equilibrium:

$$
T_{\text {vap }, 0}=T_{\text {liq }, 0}=T_{0}
$$

with $T_{0}$ an input to the model. $V_{l i q, 0}$ is the initial volume of liquid occupying the TP-R: 


$$
V_{\text {liq }, 0}=\left(\pi \cdot R_{T P-R}^{2} \cdot x_{\text {liq }, 0}\right)-\left(\pi \cdot R_{\text {cart }}^{2} \cdot H_{\text {cart }}\right)
$$

$V_{\text {vap }, 0}$ the initial volume of vapor in the TP-R:

$$
V_{\text {vap }, 0}=V_{T P-R}-V_{\text {liq }, 0}
$$

\section{The temperature of liquid $T_{l i q}(t)$}

\section{Equations of energy conservation}

The thermal junction $0_{t}$ allows to write the following enthalpy flow balance:

$$
\dot{H}_{l i q \_a c c}=\left(\dot{H}_{c o n d / l i q}+\dot{H}_{c a r t / l i q}\right)-\left(\dot{H}_{l i q / v a p}+\dot{H}_{l i q / w a l l \_i n t}{ }_{\text {inf }}\right)
$$

The enthalpy storage in the volume $V_{l i q}$ is modeled (Figure 5) by the element $C_{l i q}$ :

$$
H_{l i q_{-} a c c}(t)=\int_{t} \dot{H}_{l i q_{-} a c c}(t) \cdot d t+H_{l i q, 0}
$$

where $H_{l i q, 0}$ is the initial enthalpy in the control volume. The constitutive law of the element $C_{\text {liquid }}$ is then:

$$
T_{l i q}(t)=\frac{H_{l i q_{\_} a c c}(t)}{m_{l i q_{-} a c c}(t) \cdot c_{p, l i q}}
$$

The accumulated mass of the liquid $m_{\text {liq_acc }}(t)$ is given by equation (4).

\section{b) Volume $V_{\text {Wall_inf }}$}

\section{The temperature of the walls $T_{\text {wall }}(t)$}

The thermal junction $0_{t}$ allows writing the following enthalpy flow balance:

$$
\dot{H}_{\text {wall }_{\text {inf }} \text { acc }}=\left(\dot{H}_{\text {liq/wall_int }}{ }_{\text {iff }}\right)-\left(\dot{H}_{\text {cart } / l i q}+\dot{H}_{\text {air/wall_ext }} \text { inf }\right)
$$

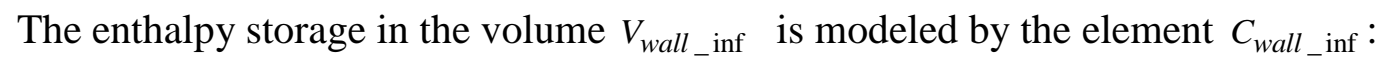

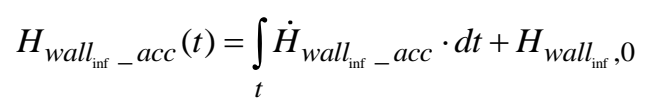

The constitutive law of the element $C_{\text {wall_inf }}$ is then:

$$
T_{\text {wall }_{\text {liff }}}(t)=\frac{H_{\text {wall }_{\text {inf }} a c c}(t)}{m_{\text {wall }_{\text {inf }}}(t) \cdot c_{p, \text { wall }}}
$$

c) Volume $V_{\text {Wall_sup }}$

The temperature of the wall $T_{\text {wall }}(t)$

The formalism related describing the element $C_{\text {wall_sup }}$ is similar to the that one of $C_{\text {wall }}$ inf . 


\section{d) Volume $V_{\text {Wall_cart }}$}

$>$ The temperature of the cartridge $T_{\text {cart }}(t)$

The thermal junction $0_{t}$ allows to write the following enthalpy flow balance:

$$
\dot{H}_{\text {cart_acc }}=P-\dot{H}_{\text {ext_cart }}
$$

where $\mathrm{P}$ the thermal power provided by the cartridge. The enthalpy storage in the volume $V_{\text {wall_cart }}$ is modeled by the element $C_{\text {wall_cart }}$ :

$$
H_{\text {cart_acc }}(t)=\int_{t} \dot{H}_{c a r t \_a c c} \cdot d t+H_{c a r t, 0}
$$

The constitutive law of the element $C_{\text {wall_cart }}$ is then:

$$
T_{\text {cart }}(t)=\frac{H_{\text {cart_acc }}(t)}{m_{\text {cart }}(t) \cdot c_{p, \text { cart }}}
$$

e) Volume $V_{\text {vap }}$

The vapor mass $m_{v a p_{2} a c c}$

The vapor mass stored inside the volume $V_{v a p}$ is modeled using the bond graph element $C_{v a p}$ with the same developments shown in section (2.3.b).

\section{The pressure of the vapor $P_{v a p}(t)$}

The vapor volume is saturated which allows to write the vapor pressure $P_{v a p}$ as function of steam density $\rho_{\text {vap }}$. The relationship between the two variables is obtained using thermodynamic tables provided by NIST [site1]. An interpolation function is then developed and valid for $\left[0.0049 ; 0.91 \mathrm{~kg} / \mathrm{m}^{3}\right]$ :

$$
P_{\text {vap }}\left(\rho_{\text {vap }}\right)=\frac{0.03539 . \rho_{\text {vap }}^{3}+1.859 . \rho_{\text {vap }}^{2}+0.6709 . \rho_{\text {vap }}-0.001328}{\rho_{\text {vap }}+0.4596}
$$

\section{Remark about interpolation fonctions:}

It should be noted that the functions relating the thermodynamic quantities are valid for pressure interval of small amplitudes $[0.1 ; 1.5 \mathrm{bar}]$, that's why these functions (polynomials, Lagrangian, Gaussian) are of great precision (the correlation coefficient is equal to 1). A particular interest is devoted to the precision when developing these functions.

The steam density $\rho_{\text {vap }}(t)$ is:

$$
\rho_{\text {vap }}(t)=\frac{m_{\text {vap_acc }}(t)}{V_{\text {vap }}(t)}
$$

The vapor volume $V_{\text {vap }}(t)$ is calculated using the equation (55).

\section{$>$ The temperature of the vapor $T_{\text {vap }}(t)$}

The temperature of saturated steam in the TP-R is related to the pressure (saturation conditions). The relationship between the two variables is obtained using a Gaussian interpolation which is valid for $[0.1 ; 1.5 \mathrm{bar}]$ : 


$$
\begin{aligned}
& T_{\text {vap }}\left(P_{\text {vap }}\right)=392.7 . \exp \left(-\left(\frac{P_{\text {vap }}-3.252}{1.23}\right)^{2}\right)+273.7 \cdot \exp \left(-\left(\frac{P_{\text {vap }}-1.636}{0.7764}\right)^{2}\right) \\
& + \text { 151.1.exp }\left(-\left(\frac{P_{\text {vap }}-0.9858}{0.5366}\right)^{2}\right)+44.5 \cdot \exp \left(-\left(\frac{P_{\text {vap }}-0.6574}{0.3601}\right)^{2}\right) \\
& + \text { 297.2. } \exp \left(-\left(\frac{P_{\text {vap }}-0.1384}{0.6353}\right)^{2}\right)+52.64 . \exp \left(-\left(\frac{P_{\text {vap }}-2.414}{0.5595}\right)^{2}\right)
\end{aligned}
$$

\subsection{Description of conducto-convective flows: $R$ elements}

This section presents expressions of the eight thermal flows involved in the heating process. These flows are shown in Figure 3 and are crucial to calculate the unknowns of the problem. The thermal convective coefficients are the most complicated parameters, they are calculated using specific correlations extracted from the open literature and reported below.

a) Heat flow from the cartridge: $\dot{H}_{\text {cart/liq }}$

This term is computed in the bond graph element $R_{\text {Wall_ext_cart }}$ presented in figure 4.

Research works on heat exchanges in a closed reservoir, (Nukiyama , 1934) led to set up an experiment allowing the visualization of different flow patterns appearing during heating. An analysis of the curve obtained Figure 6 shows that heat exchange mode is strongly associated to the observed pattern (liquid, bubbles, plug, slug and annular...). It is therefore important, from a modeling point of view, to identify, first, the flow regime using appropriate indicators to apply subsequently the corresponding heat exchange coefficient. Actually, the curve of Figure 6 shows that the evolution of the heat density $q\left(w / \mathrm{m}^{2}\right)$ imposed by the heating block to the liquid depends on the difference between the temperature of the cartridge wall $T_{\text {wall,cart }}$ and the liquid temperature: $\Delta T=T_{\text {wall,cart }}-T_{\text {liq }}$. The slope of the curve $q=f(\Delta T)$ represents the famous heat exchange coefficient $h_{\text {conv }}$. A detailed study of the proposed correlations for this coefficient is discussed in this paragraph, in order to take them into account in the developed model. Finally, note that the heat flow provided by the heat source (cartridge) to the liquid is written as:

$$
\dot{H}_{\text {cart } / l i q}=h_{\text {conv }} \cdot S_{\text {cart }} \cdot\left(T_{\text {wall }, \text { cart }}-T_{\text {liq }}\right)
$$

where:

$$
S_{\text {cart }}=2 \cdot \pi \cdot R_{\text {cart }} \cdot H_{\text {cart }}
$$

\section{Heat exchange coefficients related to different flow patterns}

Nukiyama drew the graph Figure 6, in which heat flow density $q\left(w / \mathrm{cm}^{2}\right)$ is a function of : $\Delta T=T_{\text {wall }, \text { cart }}-T_{\text {liq }}$.

- Heat transfer coefficient associated with the section : OA

During this preliminary phase, the heat transfer $\dot{H}_{\text {liq/cart }}$ between the heating element and the liquid is done by convection obeying Newton's law:

$$
\dot{H}_{\text {cart lliq }}=h_{\text {conv }} \cdot S_{\text {cart }} \cdot \Delta T
$$




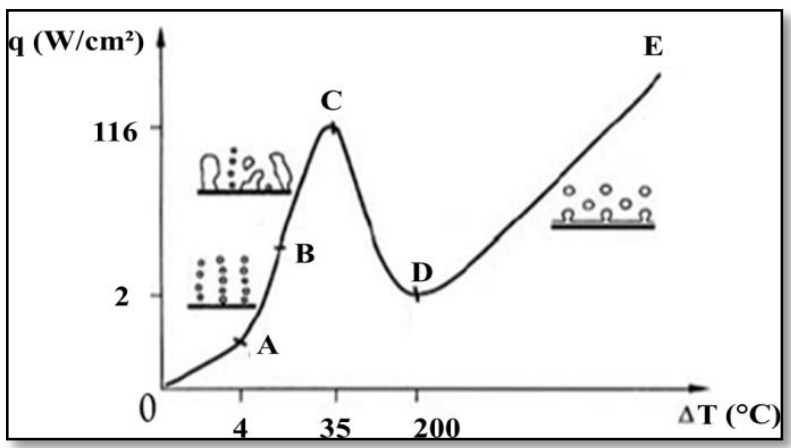

Figure 6 : Nukiyama curve specific to water [DEL90].

The convection coefficient $h_{\text {conv }}$ is calculated using Churchil and Chu correlation reported by J-M Delhaye [DEL90] and valid for: $10^{-5} \leq R a \leq 10^{12}$. In our case the value of Ra number is about $8 \cdot 10^{5}$ :

$$
N u=\left(0.60 \cdot \frac{0.387 \cdot R a^{1 / 6}}{\left(1+\left(\frac{0.559}{\operatorname{Pr}}\right)^{9 / 16}\right)^{8 / 27}}\right)^{2}
$$

The following numbers are defined:

$\Rightarrow$ Nusselt number :

$$
N u=\frac{h_{\text {conv }} \cdot d_{\text {cart }}}{\lambda_{\text {liq }}}=\frac{q \cdot d_{\text {cart }}}{\Delta T \cdot \lambda_{\text {liq }}}
$$

$\Rightarrow$ Rayleigh number

$$
R a=\frac{g \cdot \beta_{l i q} \cdot \Delta T \cdot d_{\text {cart }}^{3}}{\lambda_{\text {liq }} \cdot \alpha_{l i q}}
$$

$\Rightarrow$ Prandtl number :

$$
\operatorname{Pr}=\frac{v_{l i q}}{\alpha_{l i q}}
$$

- Heat transfer coefficient associated with the section AC : towards a Saturated Nucleate Boiling (SNB):

Section AB: Nucleate boiling with isolated bubbles. Bubbles of vapor (or nucleation sites), are regularly distributed along the heating zone. They appear at this area and move in the form of steam columns towards the liquid/vapor interface of TP-R. At this interface, bubbles will evaporate increasing thereby the vapor pressure in the upper part of the two-phase reservoir.

Section BC : Saturated Nucleate Boiling (SNB) with slug forms. Vapor bubbles chaplets proliferate as long as the heat flux is emitted by the cartridge. They have shapes of slugs or vapor columns [DEL90]. Slugs intensify until they substantially isolate the entire exchange surface with a very unstable vapor film. The heat flow used to heat up the liquid is mainly due to the latent heat of vaporization.

The heat flux density $q$ transferred along the AC section presented in Figure 6 is calculated using the correlation of Rohsenow [ROH85]: 


$$
\frac{c_{\text {wall }, \text { liq }} \cdot\left(T_{\text {wall }, \text { cart }}-T_{\text {sat }}\right)}{L_{v}}=C_{s f} \cdot\left[\frac{q}{\mu_{\text {liq }} \cdot L_{v}} \cdot \sqrt{\frac{\sigma}{g \cdot\left(\rho_{\text {liq }}-\rho_{\text {vap }}\right)}}\right]^{0.33} \cdot\left(\frac{\mu_{\text {liq }} \cdot c_{p, l i q}}{\lambda_{\text {liq }}}\right)^{s}
$$

Rohsenow suggests the following values: $s=1$ for water. As for the coefficient $C_{s f}$, the value $C_{s f}=0.013$ is recommended.

\section{Indicator detecting the change of the flow pattern: OA or AC section?}

From a modeling standpoint, it is necessary to write an indicator making the code able to switch from the correlation of Churchil and Chu to the Rohsenow correlation.

According to the Figure 6, one can note that it is not enough to have the equality $T_{\text {wall,cart }}=T_{\text {sat }}$ to attend the birth of vapor bubbles. Actually, an additional overheating is needed before speaking of saturated nucleate boiling (SNB). This overheating is mainly related to the cavity radius of vapor bubbles $r_{c a v}$ and interfacial tension $\sigma$, which exists at the interface between the liquid and vapor. As a first approximation, overheating needed to launch the SNB can be calculated as follows [DEL90]

$$
\Delta T_{\text {sat }}=T_{\text {wall }, \text { cart }}-T_{\text {sat }}=\frac{2 \cdot \sigma \cdot T_{\text {sat }}}{r_{\text {cav }} \cdot L_{v} \cdot \rho_{\text {vap }}}
$$

Radius cavities $r_{c a v}$ at a smooth metal surface is about: $r_{c a v}=5 \mu m$ for water [DEL90].So that, the indicator ind $_{S N B}$ programmed in the model is as follows:

If:

$$
T_{\text {wall,cart }}-T_{\text {sat }}>\frac{2 \cdot \sigma \cdot T_{\text {sat }}}{r_{\text {cav }} \cdot L_{v} \cdot \rho_{\text {vap }}}
$$

then: $S N B=1$, this means that the (SNB) is initiated, and the correlation used is the Rohsenow equation (28). Otherwise $S N B=0$, there is not yet $(\mathrm{SNB})$ and the used correlation is then the Churchil and Chu equation (24).

Point C: known as the boiling crisis point, or burn out.

If the critical flow $q_{\text {crit }}$ density is reached, then a volume of steam envelops the entire exchange surface as shown in Figure 7, causing thereby a separation between the liquid and the cartridge.

Nukiyama experience shows that during a critical flow, the quantity $\Delta T=T_{\text {wall,cart }}-T_{\text {liq }}$ increases very quickly, as it is visible in Figure 6. It is manifested in reality by a consequent increase in the wall temperature of the heating cartridge which can easily exceed its melting temperature $\left(1000^{\circ} \mathrm{C}\right)$ and therefore a degraded cartridge.

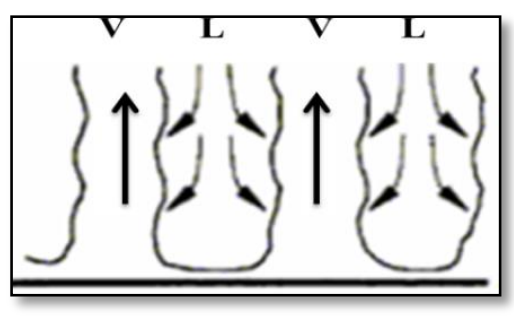

Figure 7 : boiling crisis. 
The critical flow density is calculated in the proposed model of TP-R. If ever this value is reached the model user knows it. This is an output of the model.

The selected correlation of $q_{c r i t}$ is the one of Sun and Lienhard reported by J-M Delhaye [DEL90] :

$$
q_{\text {crit }}=\left[0.116+0.3 \cdot \exp \left(-3.44 \cdot R_{*}^{1 / 2}\right)\right] \cdot L_{v} \cdot \rho_{\text {vap }}^{1 / 2} \cdot\left[\sigma \cdot\left(\rho_{\text {liq }}-\rho_{\text {vap }}\right) \cdot g\right]^{1 / 4}
$$

where $R_{*}$ is a dimensionless radius whose expression is:

$$
R_{*}=R_{\text {cart }} \cdot\left[\frac{\sigma}{g \cdot\left(\rho_{\text {liq }}-\rho_{\text {vap }}\right)}\right]^{-1 / 2}
$$

\section{b) Heat flow exchanged between the liquid and the wall: $\dot{H}_{\text {liq/wall }}$ int $_{\text {int }}$}

This term is computed in the bond graph element $R_{\text {Wall_int_inf }}$ presented in figure 4.

Heat losses transferred from the liquid to the outside of the TP-R, are the consequence of three modes of heat transfer:

\section{Natural convection between liquid and the inner wall}

The heat transfer coefficient is given by:

$$
\begin{gathered}
h_{\mathrm{int}}=\frac{N u \cdot \lambda_{l i q}}{D_{T P-R}} \\
N u=C \cdot(G r \cdot \operatorname{Pr})^{m}
\end{gathered}
$$

where:

If $(G r \cdot \operatorname{Pr}) \in\left[10^{4}, 10^{9}\right]$ then : $C=0.59$ and $m=1 / 4$.

If $(G r \cdot \operatorname{Pr}) \in\left[10^{9}, 10^{13}\right]$ then : $\quad C=0.021$ and $m=2 / 5$.

- The number Pr is given by equation (27). $G r$ is the Grashof number defined as :

$$
G r=\frac{D_{T P-R}^{3} \cdot \rho_{l i q}^{2} \cdot g \cdot \beta \cdot \Delta T}{\mu_{l i q}^{2}}
$$

Finally, the heat flow transferred by natural convection is:

with:

$$
\dot{H}_{\text {liq/wall_int }} \mathrm{inf}_{\mathrm{int}}=h_{\mathrm{int}} \cdot S_{\mathrm{int}_{\mathrm{inf}}} \cdot\left(T_{\text {liq }}-T_{\text {wall_int }_{\mathrm{inf}}}\right)
$$

$$
S_{\text {int }_{\text {inf }}}=2 \cdot \pi \cdot R_{T P-R} \cdot x_{l i q}
$$

\section{Radial conduction inside the wall}

The analytical expression for the thermal resistance inside of a hollow cylinder is: 


$$
R=\frac{\ln \left(\frac{R_{T P-R, e x t}}{R_{T P-R, \text { int }}}\right)}{2 \cdot \pi \cdot \lambda_{T P-R} \cdot x_{l i q}}
$$

Thus, the radial heat flow transferred by conduction through the wall of the TP-R is written according to Newton's law:

$$
\dot{Q}_{\text {wall }}=\frac{1}{R} \cdot\left(T_{\text {wall_ }_{-} \mathrm{int}_{\mathrm{inf}}}-T_{\text {wall_ext }_{\mathrm{inf}}}\right)
$$

\section{Natural convection between wall and air.}

The heat transfer coefficient by laminar convection is written as:

$$
h_{\text {ext }}=1.42 \cdot\left(\frac{\Delta T}{x_{\text {liq }}}\right)^{0.25}
$$

with:

$$
\Delta T=T_{\text {wall_ext }_{\text {inf }}}-T_{\text {air }}
$$

This expression of $h_{\text {ext }}$ implies a laminar flow regime air/wall. In other words, it is valid for a number of Grashof below than: $10^{9}$, which is largely respected in our case. Thus, the heat flow transferred by convection is:

$$
\dot{H}_{\text {air_ext } / \text { wall_ext }} \text { inf }_{\text {inf }}=h_{\text {ext }} \cdot S_{\text {ext }} \cdot\left(T_{\text {inf }} \text { wall_ext } t_{\text {inf }}-T_{\text {air }}\right)
$$

where:

$$
S_{\text {ext } t_{\mathrm{inf}}}=2 \cdot \pi \cdot\left(R_{T P-R}+e_{T P-R}\right) \cdot x_{l i q}
$$

c) Heat flow between liquid and the condensate film: $\dot{H}_{\text {cond /liq }}$

This term is computed in the bond graph element $R_{\text {Wall_int_sup }}$ presented in figure 4.

The enthalpy flow rate received by the liquid from the condensate film is:

$$
\dot{H}_{\text {cond } / l i q}=\dot{m}_{\text {cond }} \cdot c_{p, l i q} \cdot T_{\text {vap }}
$$

The Annex $\mathrm{C}$ shows how to determine the analytical expression of the Mass flow of condensation $\dot{m}_{\text {cond }}$. Its formula is given by equation (52). Expressions of other quantities involved in the condensation phenomenon such as film width equation (53), and the flow velocity $v_{\text {cond }}$ of condensate film are also established in the Annex C. The term of specific heat $c_{p, l i q}$ is calculated based on the temperature of the condensate film $T_{v a p}$ according to the relationship (A. 3) .

\section{d) Heat flow exchanged between liquid and vapor: $\dot{H}_{\text {liq/vap }}$}

This term is computed in the bond graph element $R_{\text {Inter_liq_vap }}$ presented in figure 4 .

At the evaporation interface, the vapor bubbles leave the liquid to go into the vapor space. These bubbles carry with them some enthalpy flow (quantity of heat) whose expression is:

$$
\dot{H}_{\text {liq/vap }}=\dot{m}_{\text {evap }} \cdot c_{p, l i q} \cdot T_{\text {liq }}
$$

Expression of $c_{p, l i q}$ is calculated by equation (A. 3 ). The term $\dot{m}_{\text {evap }}$ is given equation (58). 


\section{e) Longitudinal heat flow propagated by conduction along the wall: $\dot{Q}_{\text {ton }}$}

This term is computed in the bond graph element $R_{\text {Wall }}$ presented in figure 4 .

TP-R is a cylinder of an outer diameter: $D_{T P-R_{-} e x t}$, and an internal diameter: $d_{T P-R_{-} \text {int }}$, its cross section is then:

$$
S_{T P-R}=\frac{\pi}{4} \cdot\left(D_{T P-R_{-} e x t}^{2}-d_{T P-R_{-} \text {int }}^{2}\right)
$$

The heat transfer resistance is:

$$
R_{\text {long }}=\frac{H_{T P-R}}{\lambda_{T P-R} \cdot S_{T P-R}}
$$

It comes, according to the Fourier conduction law:

$$
\dot{Q}_{\text {long }}=\frac{1}{R_{\text {long }}} \cdot\left(T_{\text {wall }_{\text {inf }}}-T_{\text {wall }}\right)
$$

\section{f) Heat flow exchanged between the steam and the wall of the TP-R: $\dot{H}_{v a p / w a l l}$ int $_{\mathrm{spp}}$}

This term is computed in the bond graph element $R_{\text {Wall_int_sup }}$ presented in figure 4 .

The total specific heat $L_{v}^{*}$ transferred by the steam to the TP-R wall is the sum of two contributions: the specific heat of condensation $\Delta H_{\text {cond }}$ added to the specific heat due to subcooling of the condensate $\left(0.68 \cdot c_{p, l i q} \cdot\left(T_{\text {vap }}-T_{\text {wall_int }_{\text {sup }}}\right)\right) \cdot L_{v}^{*}$ is then :

$$
L_{v}^{*}=\Delta H_{\text {cond }}+0.68 \cdot c_{p, l i q} \cdot\left(T_{v a p}-T_{\text {wall_int }_{\text {sup }}}\right)
$$

The specific heat of condensation $\Delta H_{\text {cond }}$ is calculated using the following equation:

$$
\Delta H_{\text {cond }}\left(P_{\text {vap }}\right)=h^{\prime \prime}\left(P_{\text {vap }}\right)-h^{\prime}\left(P_{\text {vap }}\right)
$$

Functions $h^{\prime \prime}$ and $h^{\prime}$ are given in Annex C. Thus, the amount of heat $\dot{H}_{\text {vap/wall_int }}$ transferred by the steam to the wall is given by:

$$
\dot{H}_{\text {vap } / \text { wall_int }}{ }_{\text {sup }}=\dot{m}_{\text {cond }} \cdot L_{v}^{*}
$$

\subsection{Mass flow of condensation and evaporation}

The condensate mass flow expression $\dot{m}_{\text {cond }}$ is established in Annex B :

$$
\dot{m}_{\text {cond }}=\rho_{\text {liq }} \cdot \frac{\left(\rho_{\text {liq }}-\rho_{\text {vap }}\right) \cdot g \cdot \delta_{\text {film }}^{3}}{3 \cdot \mu_{\text {liq }}} \cdot\left(2 \cdot \pi \cdot R_{T P-R}\right)
$$

The expression of the condensate thickness is also obtained in Annex B:

$$
\delta_{\text {film }}=\left[\frac{4 \cdot \mu_{\text {liq }} \cdot \lambda_{\text {liq }} \cdot x_{\text {vap }} \cdot\left(T_{\text {wall_int }}{ }_{\text {sup }}-T_{\text {vap }}\right)}{g \cdot \Delta H_{\text {cond }} \cdot \rho_{\text {liq }} \cdot\left(\rho_{\text {liq }}-\rho_{\text {vap }}\right)}\right]^{1 / 4}
$$




\section{Calculation of the vapor height:}

The total geometric volume of TP-R is the sum of two volumes: liquid and vapor:

$$
V_{T P-R}=V_{l i q}+V_{v a p}
$$

Then:

$$
V_{\text {vap }}(t)=\pi \cdot R_{T P-R}^{2} \cdot x_{\text {vap }}(t)=V_{T P-R}-V_{\text {liq }}(t)=\left(\pi \cdot R_{T P-R}^{2} \cdot H_{T P-R}\right)-\left(\frac{m_{\text {liq_acc }}(t)}{\rho_{\text {liq }}}\right)
$$

And:

$$
x_{\text {vap }}(t)=\frac{\left(\pi \cdot R_{T P-R}^{2} \cdot H_{T P-R}\right)-\left(\frac{m_{l i q_{-} a c c}(t)}{\rho_{\text {liq }}}\right)}{\pi \cdot R_{T P-R}^{2}}
$$

The density $\rho_{\text {liq }}$, The viscosity $\mu_{\text {liq }}$ and The specific heat of condensation $\Delta H_{\text {cond }}$ are respectively given by equations (A. 1), (A. 5). And (50).

\section{Mass flow of evaporation}

The heat balance shows that the flow of heat transferred by the heating element to the liquid volume $\dot{H}_{\text {cart } / l i q}$ is the sum of two contributions:

- The evaporation flow whose term is $\left(\dot{m}_{\text {evap }} \cdot \Delta H_{\text {evap }}\right)$.

- The leakage flow $\left(\dot{m}_{\text {evap }} \cdot c_{p, l i q} \cdot\left(T_{l i q}-T_{\text {liq }, 0}\right)\right)$, used to bring the temperature of the liquid mass to its saturation temperature.

Then:

$$
\dot{H}_{\text {cartlliq }}=\dot{m}_{\text {evap }} \cdot \Delta H_{\text {evap }}+\dot{m}_{\text {evap }} \cdot c_{p, l i q} \cdot\left(T_{\text {liq }}-T_{\text {liq }, 0}\right)
$$

where

$$
\dot{m}_{\text {evap }}=\frac{\dot{H}_{\text {cart } / l i q}}{\left(\Delta H_{\text {evap }}+c_{p, l i q} \cdot\left(T_{l i q}-T_{\text {liq }, 0}\right)\right)}
$$

\section{EXPERIMENTAL VALIDATION OF TRANSIENT THERMO HYDRAULIC MODEL OF THE TP-R}

An experimental validation is necessary to evaluate the ability of the model to predict the thermo hydraulic behavior of a TP-R. After the description of the used test bench we propose two validation tests in which comparisons between time evolution of the measured and simulated pressures and temperatures are performed. Also, the dynamic model was lately tested for other power densities ranging from $1 \mathrm{~W}$ to $200 \mathrm{~W}$ (the maximal power delivered by the cartridge), the model showed good agreement with experimental data extracted from the same test rig, which leads to consider that the model is valid for all the domain of our application. 


\subsection{Test rig description}

The test bench used in this study is developed in cooperation between LML, CRYStAL laboratories and Atmostat Company. As shown in Figure 8, the TP-R is equipped with:

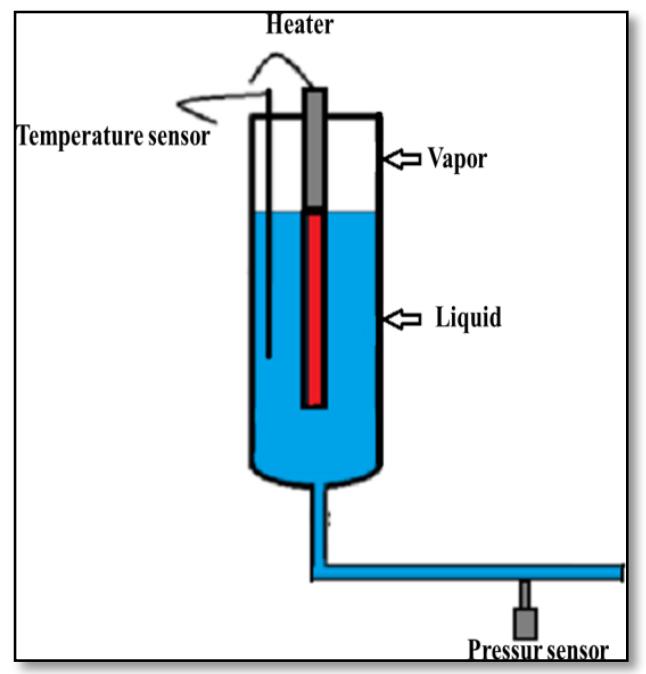

Figure 8 : TP-R instrumentation.

- K-type thermocouple, manufactured by TC direct. Its reference is 408-056 with a precision of: $+/-1^{\circ} \mathrm{C}$. The thermocouple is completely immersed in the liquid.

- Pressure sensor manufactured by Keller Serie 23. Its reference is: PAA-23/25, with a precision of $+/-0.5 \%$.

\section{Applied constraints}

A crenel of power is applied to the heating block housed in the TP-R. The ambient temperature is $20^{\circ} \mathrm{C}$.

\subsection{Experiments}

$\Rightarrow$ First validation test: crenel of amplitude $90 \mathrm{~W}$.

The initial temperature of the liquid contained in the TP-R is $20^{\circ} \mathrm{C}$. The whole test lasts 2160s.

$\Rightarrow$ Second validation test: crenel of amplitude $105 \mathrm{~W}$.

The initial temperature of the liquid contained in the TP-R is $57^{\circ} \mathrm{C}$. The whole test lasts 5436s.

\section{a) Temperature evolution of the liquid and vapor}

The time evolution of measured and simulated temperature of the liquid, shown in the Figure 9 for the first test and in Figure 10 for the second one is analyzed. In addition, the time evolution of the steam temperature (red curves) calculated by the model are plotted on the same figures for the sake of a comprehensive analysis. Recall that the current instrumentation bench does not allow the direct measurement of the steam temperature. The analysis begins with the observation of the liquid temperature (bleu curves) in both tests carried out. It is found that the model draws a monotonous evolution spread over two phases just like the one obtained experimentally. Hardly the heat is applied, liquid temperature starts increasing almost linearly until the exact moment when we cut the heat flow. At this time the 
temperature gradually falls until it stabilizes at a value corresponding to the second permanent regime. Both figures 10 and 11 show a clear ability of the model to predict the thermal behavior of the reservoir during two simultaneous transient. The first transient corresponding to the heating phases seems to be well estimated. This reflects the fact that numerous heat exchange coefficients implemented are representative of the real heat exchange taking place in the TP-R. The start of the second transitional (caused by the power cut) seems to be less well reflected. Note also that in addition to measurement uncertainties $\left(1.5^{\circ} \mathrm{C}\right)$, the observed difference may also be related to the discretization into 5 volumes. Actually, the cell containing the liquid is represented by a single control volume whose temperature is assumed to be homogeneous. In fact, the dynamics of heat transfer within the liquid is in the form of convective cells, which, to be faithfully represented, requires the inclusion of a stratification of the volume. So, as one might expect, the need for a finer discretization would be interesting. That said, the difference between measured and simulated results decreases rapidly to become practically zero as it approaches to the steady state. This latter is established very slowly by conducto-convective heat exchange with the external environment which remains poorly insulated. Concordance between measurements and simulation results proves the validity of the selected heat transfer coefficients.

Given the temporal evolution of the liquid temperature, the transient thermo hydraulic model of TP-R seems to estimate well the thermal dynamics with identical slopes between model and measures.

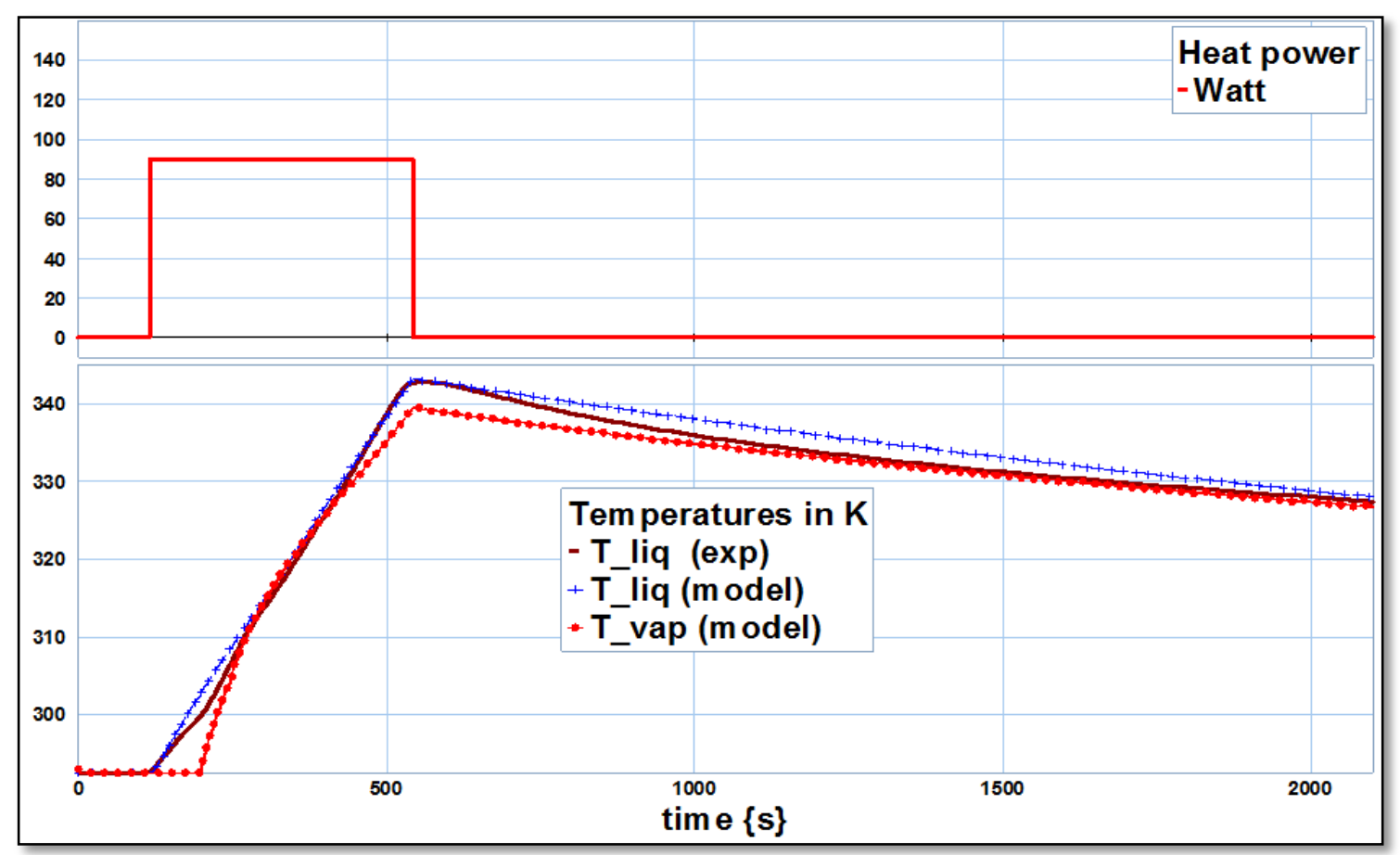

Figure 9 : Time evolution of liquid and vapor temperature of (Test 1). 


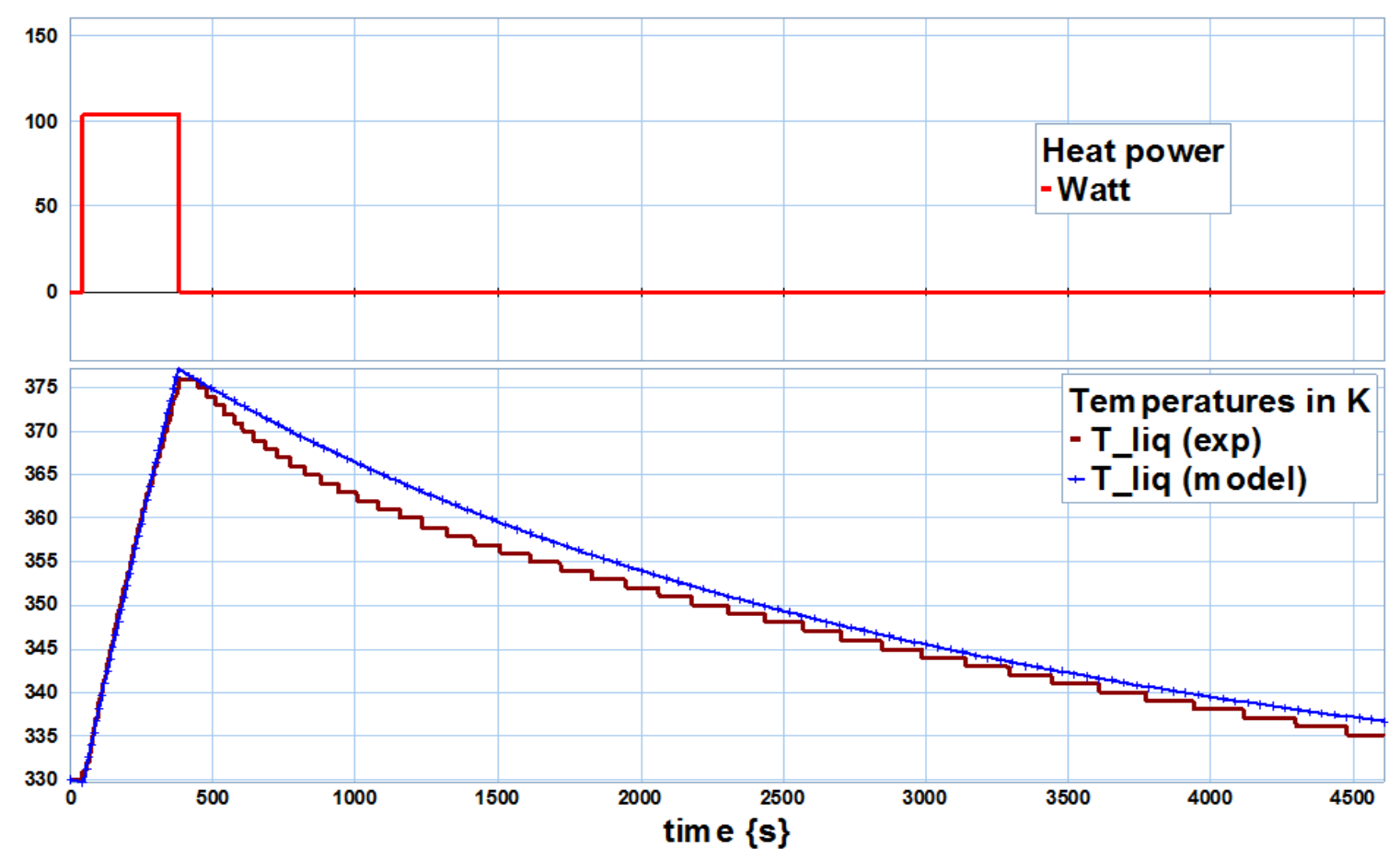

Figure 10: Time evolution of liquid and vapor temperature (Test 2).

\section{b) Evolution of liquid and steam pressure}

The temporal evolution of the liquid pressure plotted in figures 11 and 12 is now examined. Once again, the bench instrumentation does not give access to the vapor pressure. The calculated and measured values agree well during steady states. As for the transitional phase, the model generally predicts a monotonic increase in two parts, joining so the experimental data. The slopes during the heating phase seem to be well estimated by the model. However a slight overestimation of pressure during descent phases is observed. The reason is contained in the assumption of thermodynamic equilibrium of the steam. Actually, this assumption leads to a vapor pressure always function of density, whereas this pressure is rigorously depending on the density but also on the temperature. More experimental tests with different power level applied to the heating bloc would measure the validity of this hypothesis.

We should note that the bond graph approach adopted in these work and even making its particularity allows with great flexibility to apply the conservation laws on the steam volume and deduce the temperature and pressure without using the hypothesis of saturation state, which, according to the two validation tests, seems to be not too restrictive.

\section{c) Vapor pressure}

The transient model seems to predict well the temporal evolution of the liquid pressure. This shows that:

- Since the liquid pressure is calculated by simple application of hydrostatic law, it is indeed pressure vapor which is indirectly validated by the tests. And through this well estimated steam pressure, all modeled phenomena (evaporation, condensation and compressionexpansion steam) are finally well modeled.

- The height of the liquid intervening in the hydrostatic law as plotted in Figure 13, is also implicitly validated. 


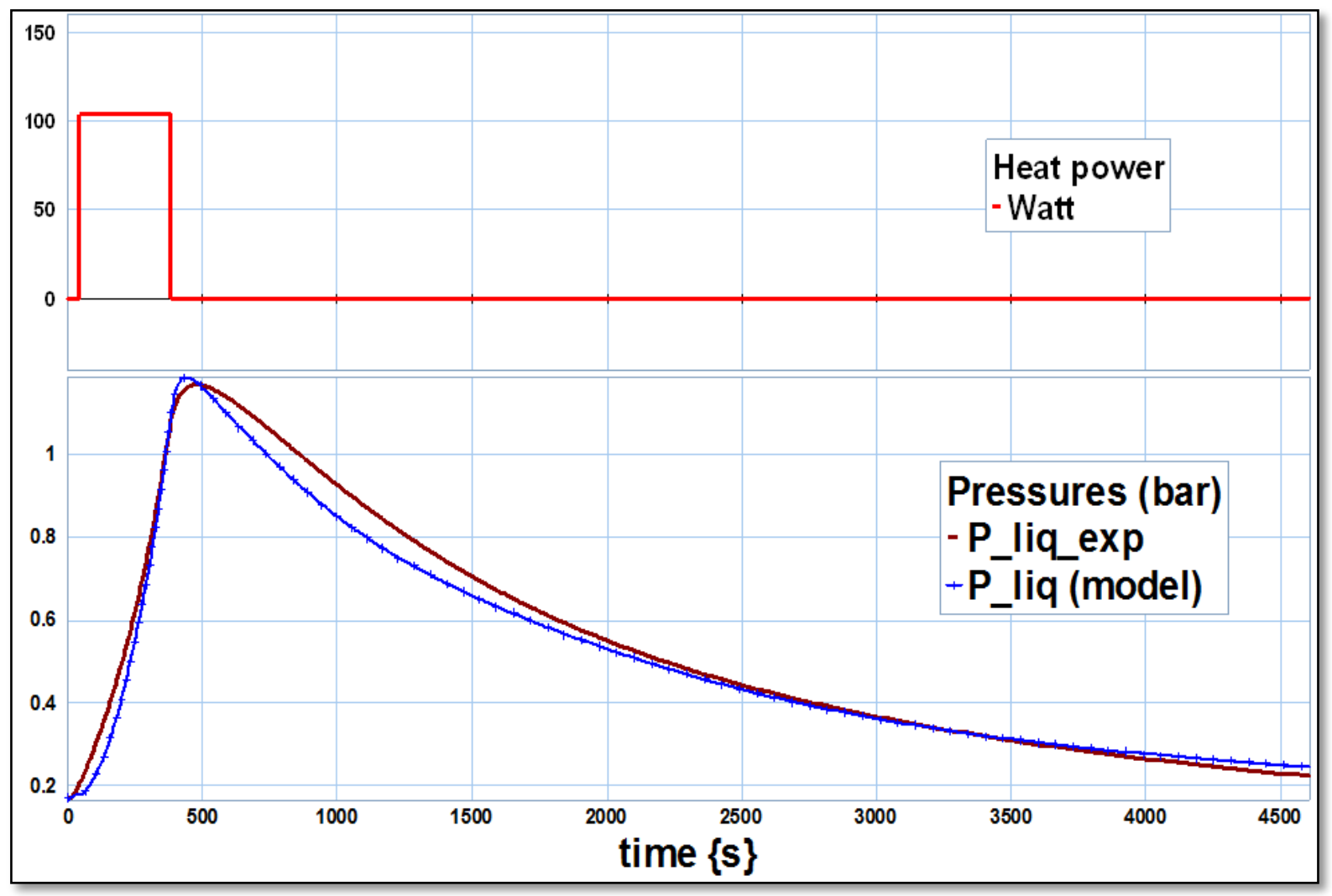

Figure 11: Time evolution of the pressure of liquid and vapor (Test 1).

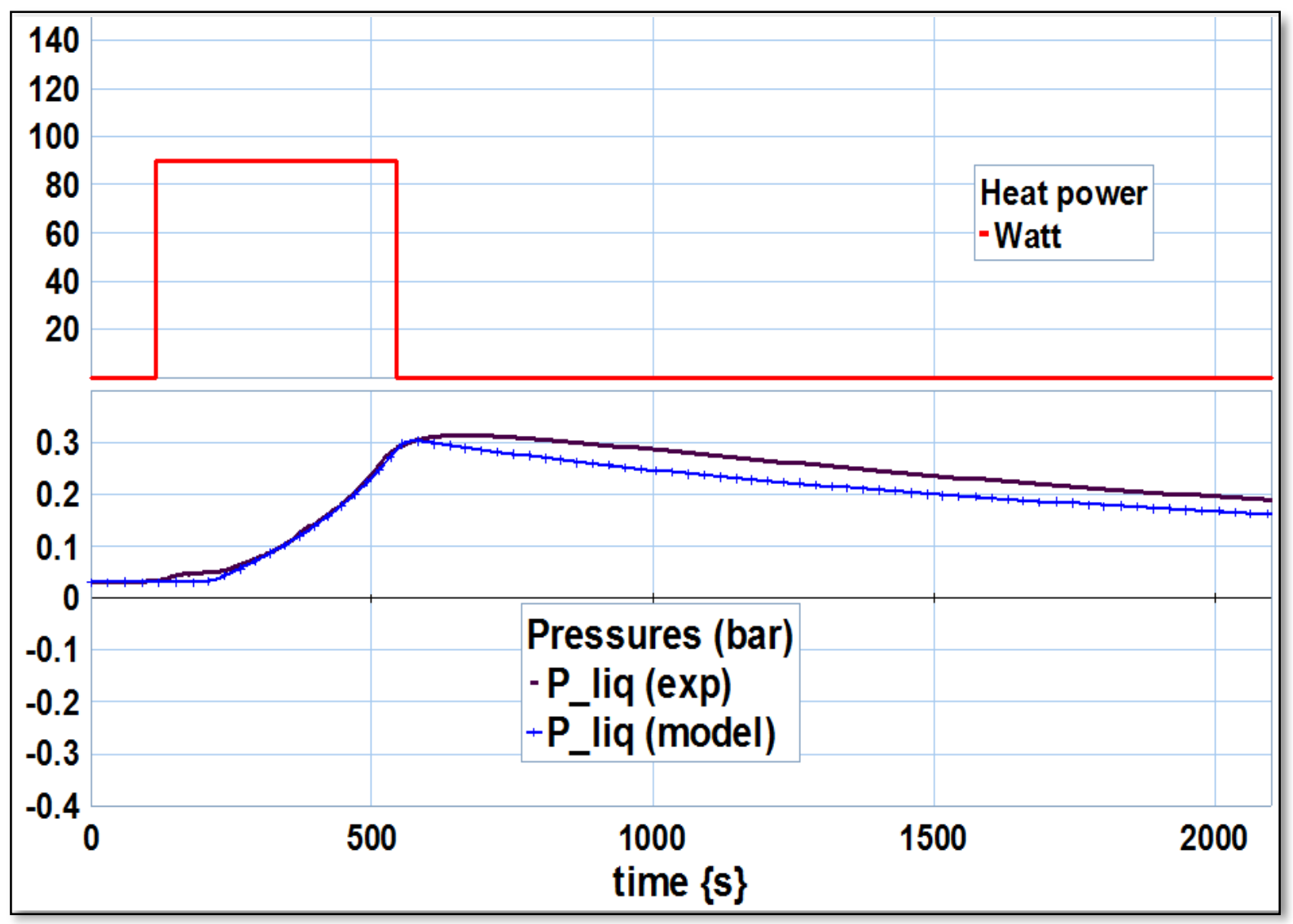

Figure 12: Time evolution of the pressure of liquid and vapor (Test 2). 


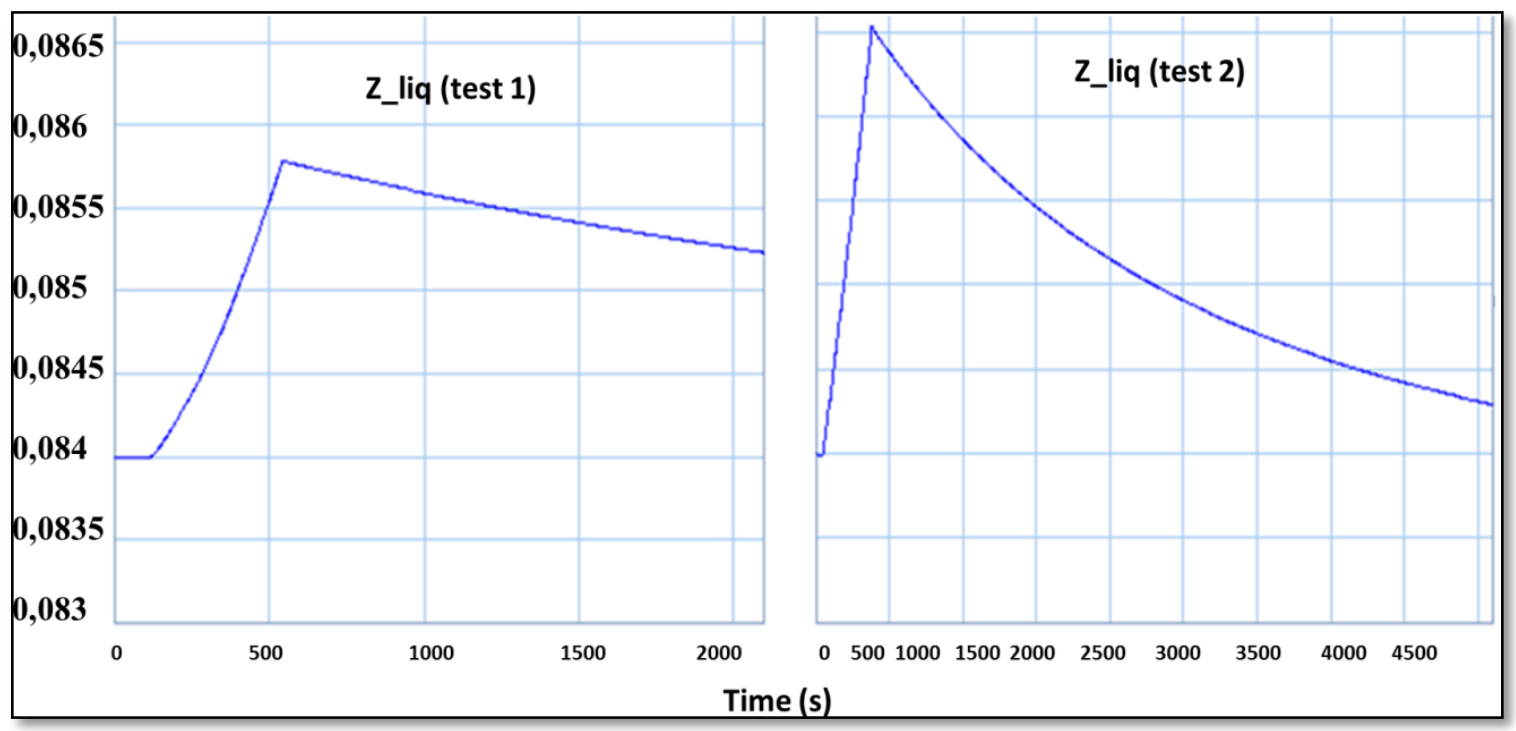

Figure 13: Time evolution of the liquid height (left: test 1, right: test 2).

\section{CONCLUSION}

This article proposes a pseudo-bond graph model dedicated to the analysis of thermo hydraulic dynamics in a TP-R. A detailed description of the complex phenomena and the constitutive equations of the different elements constituting the dynamic bond graph model are given. The validation of bond graph model is presented. Simulation results for an applied power ranging from 0 to $200 \mathrm{~W}$ are successfully confronted with experimental. Also, the model is validated for densities from 0.0045 to $0.91 \mathrm{~kg} / \mathrm{m}^{3}$ and pressures ranging from 0.1 to 2.5 bar."

It turns out that the model is able to predict with good accuracy the dynamics of thermo hydraulic behavior of the TP-R, except for a slight overestimation of pressure. However, analyzes raise two points, which worth to be recalled here: the level of discretization and saturation hypothesis both having a tangible impact on the observed differences in pressure.

The model owes its originality first to the bond graph approach, and various thermo hydraulic phenomena processed and modeled without any recalibration with experience. The literature review presents clearly that no similar modeling work was practiced. Several authors argue that the modeling of TP-R integrated into the cooling loops lack of finesse in the way they are modeled. Also, remember that the developed model can be used as a basis for the development of other more accurate solutions while its structure remains the same. Indeed, as previously reported, the bond graph is structural and it is possible to enrich the model taking into account other phenomena without any modification of the basic model. For example, it would be possible to model other heat fluxes that have not been modeled, or take into account the presence of non-condensable gas in the TP-R, or refine the discretization of the liquid and the steam volumes or the TP-R walls volume, as it may be possible to model the convective cells with more precision...

\section{NOMENClAtURE}

$\begin{array}{lll}B i & \text { Biot number } & -- \\ c_{p} & \text { specific heat } & J / \mathrm{kg} \cdot \mathrm{K} \\ d & \text { internal diameter } & \mathrm{m}\end{array}$




\begin{tabular}{|c|c|c|}
\hline$D$ & Exterior diameter & $m$ \\
\hline$e$ & wall thickness & $m$ \\
\hline$f$ & coefficient of friction & -- \\
\hline$F$ & force & $N$ \\
\hline$g$ & acceleration of gravity at the surface & $m / s^{2}$ \\
\hline$G r$ & Grashof number & -- \\
\hline$h$ & heat transfer coefficient & $W / m^{2} \cdot K$ \\
\hline$H$ & enthalpy & $W$ \\
\hline$H_{T P-R}$ & Height of the two phase reservoir & $m$ \\
\hline$\Delta H_{\text {cond }}$ & specific heat of condensation & $\mathrm{J} / \mathrm{kg} \cdot \mathrm{s}$ \\
\hline$h^{\prime}$ & specific heat of the liquid portion & $J / k g$ \\
\hline$h^{\prime \prime}$ & specific heat of the vapor portion & $J / k g$ \\
\hline$\dot{H}$ & flow enthalpy & $J / s$ \\
\hline$I$ & current intensity & $A$ \\
\hline$l$ & length of heating & $m$ \\
\hline$L_{v}$ & Specific heat of vaporization. & $\mathrm{J} / \mathrm{kg} \cdot \mathrm{s}$ \\
\hline$m$ & mass & $k g$ \\
\hline$\dot{m}$ & Mass flow & $\mathrm{kg} / \mathrm{s}$ \\
\hline $\mathrm{Nu}$ & Nusselt number & -- \\
\hline$P$ & electric power & $J / s$ \\
\hline $\operatorname{Pr}$ & Prandtl number & -- \\
\hline$q$ & Density of heat flux & $W / m^{2}$ \\
\hline$\dot{Q}$ & heat flow & $J / s$ \\
\hline$R_{*}$ & dimensionless radius & -- \\
\hline$R$ & Radius & $m$ \\
\hline$R a$ & Rayleigh number & -- \\
\hline $\operatorname{Re}$ & Reynolds number & -- \\
\hline$R$ & thermal resistance & $K / W$ \\
\hline$S$ & surface & $m^{2}$ \\
\hline$t$ & time & $s$ \\
\hline$T$ & temperature & $K$ \\
\hline$U$ & tension & $V$ \\
\hline$V$ & volume & $m^{3}$ \\
\hline$x$ & height & $m$ \\
\hline$\alpha$ & thermal diffusivity & $\mathrm{m}^{2} / \mathrm{s}$ \\
\hline$\beta$ & volume expansion coefficient & $1 / K$ \\
\hline$\rho$ & density & $\mathrm{kg} / \mathrm{m}^{3}$ \\
\hline$\mu$ & dynamic viscosity & $P a \cdot s$ \\
\hline$\sigma$ & interfacial tension & $J / m^{2}$ \\
\hline$\delta$ & thickness of the condensate film & $\mathrm{m} / \mathrm{s}^{2}$ \\
\hline$\lambda$ & thermal conductivity & $W / m \cdot K$ \\
\hline$v$ & velocity & $m / s$ \\
\hline$v_{\text {cond }}$ & Condensate velocity & $\mathrm{m} / \mathrm{s}$ \\
\hline$\Phi$ & Density of thermal flux & $J / s$ \\
\hline \multicolumn{3}{|l|}{$\underline{\text { index }}$} \\
\hline 0 & initial state & \\
\hline$a c c$ & accumulation & \\
\hline air & ambient air & \\
\hline boucle & loop & \\
\hline cart & cartridge & \\
\hline$c a v$ & cavity & \\
\hline cond & condensation & \\
\hline cons & Set point & \\
\hline $\operatorname{conv}$ & convection & \\
\hline$S N B$ & saturated nucleate boiling & \\
\hline evap & evaporation & \\
\hline ext & outside & \\
\hline 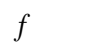 & friction & \\
\hline
\end{tabular}




$\begin{array}{ll}\text { film } & \text { Condensate film } \\ \text { int } & \text { inside } \\ \text { GNC } & \text { non-condensable gases } \\ \text { long } & \text { longitudinal } \\ \text { liq } & \text { liquid } \\ \text { wall } & \text { TP-R wall } \\ \text { sat } & \text { saturation } \\ \text { vap } & \text { vapor } \\ \text { TP-R } & \text { Two Phase Reservoir } \\ \Delta & \text { difference } \\ \text { LML } & \text { Laboratoire de mécanique de Lille }\end{array}$

\section{ACKNOWLEDGMENT}

The current research work is part of the collaborative project FUI THERMOFLUIDE-RT labeled by the competitively pole ASTech and involving three major groups (Zodiac DS, Safran Hispano, and MBDA), four SMEs (Atmostat Alcen, ADR, AER and ControlSys) and five research laboratories (CRIStAL Ecole Centrale de Lille, LML Arts et Métiers Paris Tech, LEGI Grenoble, LMT ENS Cachan, CEA-Liten Grenoble).

The authors gratefully acknowledge Mr J. Duval from Atmostat Company for the multiple fruitful scientific discussions.

\section{REFERENCES}

[GDT99] G. Dauphin-Tanguy, A. Rahmani, C. Sueur, "Bond graph aided design of controlled systems," Simulation Practice and Theory, LAGIS: Laboratoire d'Automatique et d'informatique Industrielle de Lille, Ch.7, pp.493-513, 1999.

[KEB14] M. Kebdani, G. Dauphin-Tanguy, A. Dazin, P. Dupont, Bond Graph Model of a mechanically Pumped Biphasic Loop (MPBL), 23rd Mediterranean Conference on Control and Automation, Meliá Costa del Sol, Torremolinos, Spain, 16-19 Juin, 2015.

[KEB15] M. Turki, M. Kebdani, G. Dauphin-Tanguy, A. Dazin, P. Dupont Experimentally Validated Bond Graph Model of a Brazed Plates Condenser, International Conference on Integrated Modeling and Analysis in Applied Control and Automation (IMAACA 2015), part of I3M 2015 MultiConference, Bergeggi, Italy, September 21-23, 2015.

[DGMK78] Y. E. Dolgirev, Y. E. Gerasimov, Y. F. Maidanik, and V. M. Kiseev. Calculation of a heat pipe with separate channels for vapour and liquid. J. Eng.Phys. Thermophys., Vol. 34(No. 6) :pp. 988-994, 1978.

[FUR06] M. Furukawa. Model-based method of theoretical design analysis of a loop heat pipe. Journal of Thermophysics and Heat Transfer, Vol. 20 (No.1), January-March 2006.

[HGH03] M. Hamdan, F. M. Gerner, and H. T. Henderson. Steady state model of a loop heat pipe (lhp) with coherent porous silicon (cps) wick in the evaporator. In 19th IEEE SEMI-THERM Symposium, pages pp. 88-96, Piscataway, NJ, 11-13 March 2003.

[KKM87] J. Ku, E. J. Kroliczek, and R. McIntosh. Analytical modeling of the capillary pumped loop. In Proceedings of the sixth International Heat Pipe Conference, pp 405-415, Grenoble, France, May 1987.

[KH99] T. Kaya and T. T. Hoang. Mathematical modelling of loop heat pipes an experimental validation. Journal of Thermophysics and Heat Transfer, Vol. 13 (No. 3), July-September 1999.

[LSB08] S. Launay, V. Sartre, and J. Bonjour. Analytical model for characterization of loop heat pipes. Journal of Thermophysics and Heat Transfer, Vol. 22 (No.4), October-December 2008.

[Guo00] Guo Z.Y., Xiong D.X., Yang C., Chen M., Li Z.X. « Continuous liquid-vapor phase transition in microscale » Int. J. of Thermal Sciences, Vol $34 \mathrm{~N}^{\circ} 4$, pp 481-489, 2000.

[WMN08] G. Wang, D. Mishkinis, and D. Nikanpour. Capillary heat loop technology: Space applications and recent canadian activities. Applied thermal engineering, (No. 28): pp. 284-303, 2008.

[KPGT07] T. Kaya, R. Perez, C. Gregori, and A. Torres. Numerical simulation of transient operation of loop heat pipes. Apllied Thermal Engineering, june 2007.

[PJP04] E. Pouzet, J.L. Joly, V. Platel, J.Y. Grandpeix, and C. Butto. Dynamic response of a capillary pumped loop subjected to various heat load transients. International Journal of Heat and Mass Transfer, Vol. 47:pp. 2293-2316, 2004.

[LPDJ07] S. Launay, V. Platel, S. Dutour, and J-L Joly. Transient modelling of loop heat pipes for the oscillating behaviour study. Journal of Thermophysics and Heat Transfer, Vol. 21 (No. 3), July-September 2007.

[VR07] V.V. Vlassov and R. Riehl. Mathematical model of a loop heat pipe with cylindrical evaporator and integrated reservoir. Applied Thermal Engineering, July 2007.

[Chu03] P.Y.A. Chuang. An improved steady-state model of loop heat pipes based on experimental and theoretical analyses. PhD thesis, The Pennsylvania State University, December 2003.

[AAJK07] A. A. Adoni, A. Ambirajan, V.S. Jasvanth, and D. Kumar. Thermohydraulic modeling of capillary pumped loop and loop heat pipe. Journ

[ROH85]: W.M. ROHSENOW, J.P HARTNETT and E.N. GANIC. - Handbook of Heat Transfer Fundamentals (Manuel de base sur les transferts de chaleur). McGraw-Hill Book Company, 1985.

[ZUB58] N. Zuber, "On the stability of boiling heat transfer", Trans. ASME, vol. 80, p.711, 1958.

[DEL90] J-M DELHAYE, «Transferts de chaleur : ébullition ou condensation des corps purs », Commissariat à l’Énergie Atomique. 
[LAU06] L. Lachasagne, "Numerical modeling and experimental development of a capillary pumped two-phase loop by gravity environment: application to the cooling of power electronic components in automotive context," PhD thesis, National School of Mechanical and Aeronautical Engineering Poitiers, 2006.

[Sch63] E. SCHMIDT, VDI tables constants steam, 1963.

[Kar75] D.C. Karnopp, and R.C. Rosenberg, System dynamics, a unified approach, J Wiley, New York, NY, 1975.

[Rio16] M. C. Riofrío, N. Caney, J-A Gruss, "State of the art of efficient pumped two-phase flow cooling technologies", Applied Thermal Engineering, vol. 104, pp: 333-343, 2016.

[Ser07] V. Serin, "Hydrodynamic and thermal study of the vaporization in a square section of micro channel: application to two-phase micro capillary pumped loops," $\mathrm{PhD}$ thesis, University of Toulouse, 2007.

[site1] http://webbook.nist.gov/chemistry/fluid/index.html.fr

[Site 2] http://www.20sim.com/

\section{AnNex A}

\section{About the thermo physical properties}

The thermo physical properties of the fluid depend on its thermodynamic state. Specific correlations, based on data given by [SCH63] are used in the present work. They are proposed in the following equations

Density of liquid in $\mathrm{kg} / \mathrm{m}^{3}$ :

$$
\begin{aligned}
& \rho_{l i q}=527,3 \cdot \exp \left(-\left(\frac{T_{l i q}-174,9}{165,9}\right)^{2}\right)+855,4 \cdot \exp \left(-\left(\frac{T_{l i q}-416,5}{258,2}\right)^{2}\right)+5,948 \cdot \exp \left(-\left(\frac{T_{l i q}-441,4}{38,21}\right)^{2}\right) \\
& +0,01094 \cdot \exp \left(-\left(\frac{T_{i q}-389,8}{6,458}\right)^{2}\right)+9.13 \cdot \exp \left(-\left(\frac{T_{i q}-460,6}{26,57}\right)^{2}\right)+0.1026 \cdot \exp \left(-\left(\frac{T_{i q}-329,7}{27,77}\right)^{2}\right)
\end{aligned}
$$

Density of vapor in $\mathrm{kg} / \mathrm{m}^{3}$ :

$$
\rho_{\text {vap }}=2,883 \cdot \exp \left(-\left(\frac{T_{\text {vap }}-493,3}{37,05}\right)^{2}\right)+2,49 \cdot \exp \left(-\left(\frac{T_{\text {vap }}-481,7}{53,04}\right)^{2}\right)++2,45 \cdot \exp \left(-\left(\frac{T_{\text {vap }}-470,2}{79,93}\right)^{2}\right)
$$

Specific heat of liquid in $J / \mathrm{kg} \cdot K$ :

$$
c_{p, \text { liq }}=4709 \cdot \exp \left(-\left(\frac{T_{\text {liq }}-583,6}{408,7}\right)^{2}\right)+9669 \cdot \exp \left(-\left(\frac{T_{l i q}+48,77}{220}\right)^{2}\right)+493,9 \cdot \exp \left(-\left(\frac{T_{\text {liq }}-311,4}{109,3}\right)^{2}\right)
$$

Specific heat of the vapor in $J / \mathrm{kg} \cdot \mathrm{K}$ :

$$
c_{p, \text { vap }}=-0,1 \cdot P^{6}+2,2 \cdot P^{5}-17,7 \cdot P^{4}+70,7 \cdot P^{3}-154 \cdot P^{2}+267 \cdot P+1912,3
$$

Dynamic viscosity of the liquid in $\mathrm{Pa} \cdot \mathrm{s}$ :

$$
\begin{aligned}
& \mu_{l i q}=0,00427-0,005535 \cdot \cos \left(0,0164 \cdot T_{l i q}\right)+0,001837 \cdot \sin \left(0,0164 \cdot T_{l i q}\right) \\
& +0,001649 \cdot \cos \left(2 \cdot 0,0164 \cdot T_{l i q}\right)-0,001581 \cdot \sin \left(2 \cdot 0,0164 \cdot T_{l i q}\right) \\
& -0.0001286 \cdot \cos \left(3 \cdot 0,0164 \cdot T_{l i q}\right)+0,000389 \cdot \sin \left(3 \cdot 0,0164 \cdot T_{l i q}\right)
\end{aligned}
$$

Inter-facial tension

$$
\sigma=61.25 \cdot 10^{-5} \cdot\left(1-\frac{T_{s a t}}{T_{C}}\right)^{11 / 9}
$$




\section{ANNEX B}

\section{Mass flow of condensation}

This section has as purpose to establish the analytical expression of the Mass flow of condensation $\dot{m}_{\text {cond }}$. Other parameters used in condensation calculation such as film thickness and condensate film velocity $\left(\delta_{\text {film, }}\right.$, cond $)$ are also highlighted. A hypothesis allowing the following developments assumes that the condensate flow is laminar $\operatorname{Re} \leq 2100$. Figure B.1 represents a condensate film formed on a vertical wall. All notations used are displayed on it. To begin, let's consider the infinitesimal volume constituting a portion of the condensate film:

$$
d V=\left(L=2 \cdot \pi \cdot R_{T P-R}\right) \cdot\left(\delta_{f i l m}-y\right) \cdot d x
$$

\section{Inventory of forces applied to the volume : $d V$}

- Gravity force applied to the condensate film :

$$
F_{g}=m_{l i q} \cdot g=\rho_{l i q} \cdot d V \cdot g=\rho_{l i q} \cdot\left(2 \cdot \pi \cdot R_{T P-R}\right) \cdot\left(\delta_{f i l m}-y\right) \cdot d x \cdot g
$$

- Force corresponding to the drained steam:

$$
F_{\text {vap }}=m_{\text {vap }} \cdot g=\rho_{\text {vap }} \cdot d V \cdot g=\rho_{\text {vap }} \cdot\left(2 \cdot \pi \cdot R_{T P-R}\right) \cdot\left(\delta_{\text {film }}-y\right) \cdot d x \cdot g
$$

\section{- Force due to parietal friction :}

This force is due to the friction of the condensate against the inner $\operatorname{surface}\left(2 \cdot \pi \cdot R_{V E} \cdot d x\right)$ :

$$
F_{f}=\mu_{l i q} \cdot \frac{d v_{c o n d}}{d y} \cdot\left(2 \cdot \pi \cdot R_{T P-R} \cdot d x\right)
$$

By applying the fundamental principle of Newtonian mechanics we obtain:

$$
-F_{g}+F_{\text {vap }}+F_{f}=0
$$

The equation B. 5is simplified and gives:

$$
\rho_{\text {liq }} \cdot g \cdot\left(\delta_{\text {film }}-y\right) \cdot d x=\rho_{\text {vap }} \cdot g \cdot\left(\delta_{\text {film }}-y\right) \cdot d x+\mu_{\text {liq }} \cdot \frac{d v_{\text {cond }}}{d y}
$$

After integration of equation B. 6 between $y=0$ and $y=\delta$, with considering the initial condition $u(y=0)=0$, the following expression is obtained:

$$
v_{\text {cond }}=\frac{\left(\rho_{\text {liq }}-\rho_{\text {vap }}\right) \cdot g}{\mu_{\text {liq }}} \cdot\left(\delta_{\text {film }} \cdot y-\frac{y^{2}}{2}\right)
$$

Then we deduce the condensate mass flow $\dot{m}_{\text {cond }}$ :

$$
\dot{m}_{\text {cond }}=\int_{0}^{\delta}\left(\rho_{\text {liq }} \cdot\left(2 \cdot \pi \cdot R_{T P-R} \cdot d y\right) \cdot v_{\text {cond }}\right)
$$


Finally:

$$
\dot{m}_{\text {cond }}=\rho_{\text {liq }} \cdot \frac{\left(\rho_{\text {liq }}-\rho_{\text {vap }}\right) \cdot g \cdot \delta_{\text {film }}^{3}}{3 \cdot \mu_{\text {liq }}} \cdot\left(2 \cdot \pi \cdot R_{T P-R}\right)
$$

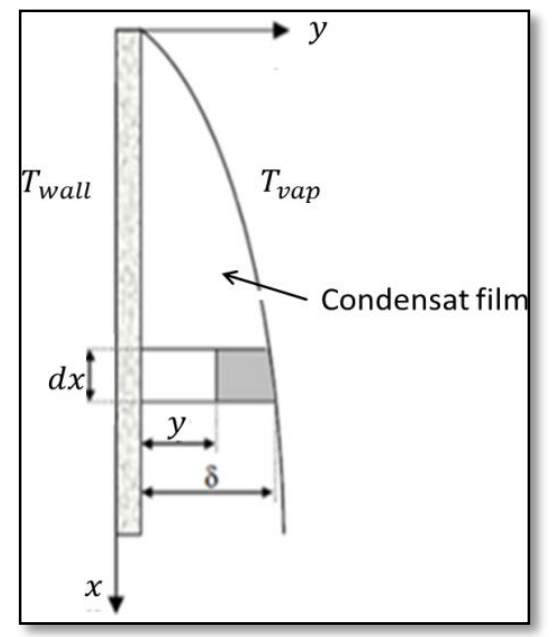

Figure B.1: Schema of the condensation process.

To determine the thickness of the condensate film $\delta_{\text {film }}$ it's considered that the enthalpy flow $\Phi$ provided by the condensate film to the wall is equal to the latent heat of condensation $\Delta H_{\text {cond }}$ equation (50) evacuated by the condensed vapor portion $\dot{m}_{\text {cond }}$. Then $\Phi=\dot{m}_{\text {cond }} \cdot \Delta H_{\text {cond }}$

- On one hand, the enthalpy flow $\Phi$ supplied by the condensate film to the wall surface $\left(2 \cdot \pi \cdot R_{T P-R} \cdot d x\right)$ is :

$$
\Phi=-\lambda \cdot\left(2 \cdot \pi \cdot R_{T P-R} \cdot d x\right) \cdot\left(\frac{\partial T}{\partial y}\right)_{y=0}=\lambda \cdot\left(2 \cdot \pi \cdot R_{T P-R} \cdot d x\right) \cdot\left(\frac{T_{\text {wall_intsup }}-T_{v a p}}{\delta_{\text {film }}}\right)
$$

- On the other hand, the condensed vapor portion $\dot{m}_{c o n d}$ can be written in the differential form:

$$
\frac{d}{d x}\left[\rho_{\text {liq }} \cdot \frac{\left(\rho_{\text {liq }}-\rho_{\text {vap }}\right) \cdot g \cdot \delta_{\text {film }}^{3}}{3 \cdot \mu_{\text {liq }}}\right] \cdot d x=\frac{d}{d \delta}\left[\rho_{\text {liq }} \cdot \frac{\left(\rho_{\text {liq }}-\rho_{\text {vap }}\right) \cdot g \cdot \delta_{\text {film }}^{3}}{3 \cdot \mu_{\text {liq }}}\right] \cdot \frac{d \delta}{d x} \cdot d x=\left[\rho_{\text {liq }} \cdot \frac{\left(\rho_{\text {liq }}-\rho_{\text {vap }}\right) \cdot g \cdot \delta_{\text {film }}^{2}}{\mu_{\text {liq }}}\right] \cdot d \delta
$$

Now, thanks to equations B. 10 and B. 11 we can rewrite the equality:

$$
\Phi=\dot{m}_{\text {cond }} \cdot \Delta H_{\text {cond }}
$$

Under the form:

$$
\lambda \cdot\left(2 \cdot \pi \cdot R_{T P-R} \cdot d x\right) \cdot\left(\frac{T_{\text {wall }_{-} \mathrm{int}_{\mathrm{sup}}}-T_{\text {vap }}}{\delta_{\text {film }}}\right)=\left[\rho_{\text {liq }} \cdot \frac{\left(\rho_{\text {liq }}-\rho_{\text {vap }}\right) \cdot g \cdot \delta_{\text {film }}^{2}}{\mu_{\text {liq }}}\right] \cdot d \delta \cdot \Delta H_{\text {cond }}
$$

Then, an integration of this equation with the boundary condition $h_{e x t}$ leads to the expression of the condensate thickness: 


$$
\delta_{\text {film }}=\left[\frac{4 \cdot \mu_{\text {liq }} \cdot \lambda_{\text {liq }} \cdot x_{\text {vap }} \cdot\left(T_{\text {wall_int }}-T_{\text {sup }}\right)}{g \cdot \Delta H_{\text {cond }} \cdot \rho_{\text {liq }} \cdot\left(\rho_{\text {liq }}-\rho_{\text {vap }}\right)}\right]^{1 / 4}
$$

The total geometric volume of TP-R is the sum of both volumes: liquid and vapor. We have:

$$
V_{T P-R}=V_{l i q}+V_{v a p}
$$

Then:

$$
V_{\text {vap }}(t)=\pi \cdot R_{V E}^{2} \cdot x_{\text {vap }}(t)=V_{T P-R}-V_{\text {liq }}(t)=\left(\pi \cdot R_{T P-R}^{2} \cdot H_{T P-R}\right)-\left(\frac{m_{\text {liq_acc }}(t)}{\rho_{\text {liq }}}\right)
$$

And:

$$
x_{\text {vap }}(t)=\frac{\left(\pi \cdot R_{T P-R}^{2} \cdot H_{T P-R}\right)-\left(\frac{m_{l i q_{-} a c c}(t)}{\rho_{\text {liq }}}\right)}{\pi \cdot R_{T P-R}^{2}}
$$

The mass of the liquid accumulated in the TP-R: $m_{\text {liq_acc }}(t)$, is calculated in the model. The density $\rho_{l i q}$ is calculated from equation A. 1.The viscosity $\mu_{l i q}$ is given by the equation (A. 5).

\section{ANNEX C}

$$
\begin{aligned}
& h^{\prime}\left(P_{\text {vap }}\right)=263,5 \cdot \exp \left(-\left(\frac{P_{\text {vap }}-0.2626}{0,1546}\right)^{2}\right)+92,88 \cdot \exp \left(-\left(\frac{P_{\text {vap }}-0,104}{0,08743}\right)^{2}\right)+34,29 \cdot \exp \left(-\left(\frac{P_{\text {vap }}-0,04696}{0,05121}\right)^{2}\right) \\
& h^{\prime \prime}\left(P_{\text {vap }}\right)=2686 \cdot \exp \left(-\left(\frac{P_{\text {vap }}-5,743}{5,795}\right)^{2}\right)+191,4 \cdot \exp \left(-\left(\frac{P_{\text {vap }}-0,06863}{0,6253}\right)^{2}\right)+79,63 \cdot \exp \left(-\left(\frac{P_{\text {vap }}-0,03843}{0,2367}\right)^{2}\right) \\
& +464,5 \cdot \exp \left(-\left(\frac{P_{\text {vap }}-0,1873}{1,363}\right)^{2}\right)+0,115 \cdot \exp \left(-\left(\frac{P_{\text {vap }}-1,844}{0,001972}\right)^{2}\right)+955,8 \cdot \exp \left(-\left(\frac{P_{\text {vap }}-1,141}{2,594}\right)^{2}\right)
\end{aligned}
$$

